\title{
Review \\ Heterocycles by Consecutive Multicomponent Syntheses via Catalytically Generated Alkynoyl Intermediates
}

\author{
Jonas Niedballa and Thomas J. J. Müller*
}

check for updates

Citation: Niedballa, J.; Müller, T.J.J. Heterocycles by Consecutive Multicomponent Syntheses via Catalytically Generated Alkynoyl Intermediates. Catalysts 2022, 12, 90 https://doi.org/10.3390/ catal12010090

Academic Editor: Antonio Salomone

Received: 13 December 2021

Accepted: 9 January 2022

Published: 13 January 2022

Publisher's Note: MDPI stays neutral with regard to jurisdictional claims in published maps and institutional affiliations.

Copyright: (C) 2022 by the authors. Licensee MDPI, Basel, Switzerland. This article is an open access article distributed under the terms and conditions of the Creative Commons Attribution (CC BY) license (https:// creativecommons.org/licenses/by/ $4.0 /)$.
Institut für Organische Chemie und Makromolekulare Chemie, Heinrich-Heine-Universität Düsseldorf, Universitätsstraße 1, D-40225 Düsseldorf, Germany; jonas-niedballa@web.de

* Correspondence: ThomasJJ.Mueller@hhu.de; Tel.: +49-211-81-12298

\begin{abstract}
Multicomponent processes are beneficial tools for the synthesis of heterocycles. As densely substituted bifunctional electrophiles, ynones are essential intermediates by applying cyclocondensations or cycloadditions in numerous heterocycle syntheses. The respective alkynoyl intermediates are generally accessible by palladium-, copper- and palladium/copper-catalyzed alkynylation. In turn, the mild reaction conditions allow for a fast and versatile entry to functional heterocycles in the sense of consecutive multicomponent processes. This review collates and presents recent advances in accessing thirteen heterocycle classes and their applications by virtue of catalytic alkynoyl generation in diversity-oriented multicomponent syntheses in a one-pot fashion.
\end{abstract}

Keywords: alkynylation; catalysis; copper; cross-coupling; heterocycles; multicomponent reactions; one-pot reactions; palladium

\section{Introduction}

Multicomponent reactions (MCRs) represent a potent and multipurpose synthetic concept, where high efficiency and abundant diversity are elegantly combined for rapidly accessing compound libraries. By definition, in MCRs at least three substrates forming two or more new bonds generate a single product in the sense of a one-pot operation, whereupon the majority of the deployed atoms of the starting materials end up in the products $[1,2]$. Therefore, MCRs rely on the repeated generation and consumption of reactive functionality in each step, strictly adhering to a one-pot process [3]. MCRs have certain advantages over classical multistep processes, because they combine efficiency and efficacy, simultaneously addressing chemo-, regio- and stereoselectivity. As a consequence, these processes rapidly lead to high levels of structural and functional diversity. As MCRs are efficient and diversityoriented syntheses they have inevitably become a superior synthetic tool. Three different classes of MCRs represent the categories to date [3]. In the domino-type reaction, all reagents are present at the outset of the process and all individual steps proceed without the possibility of isolating intermediary products. Contrary, in sequential MCR all components are added in a defined order and the reaction conditions are maintained constant. This allows for possibly isolating intermediary products. Closely related are consecutive onepot processes where reagents are subsequently likewise added, however, the ancillary possibility to alter conditions for each single step is included. A common feature of all three types is the urge to commence with highly diverse and readily accessible substrates to access a broad scope of physical and structural characteristics, warranting synthetic convergence and explorative space. Particularly in heterocycle syntheses, the versatility of carbon-carbon triple bond functionalization has turned out to be very fruitful [4]. Thus, the catalytic access to alkynes as functional groups with modulating relative reactivities is a key to MCRs, which has been increasingly developed over the past two decades [5].

Heterocyclic systems are ubiquitous both in natural products and applied chemistry and thus their MCR synthesis makes them predestined targets. Alongside their use in life sciences [6-8], heterocycles are increasingly applied in molecular electronics [9] and 
photonics [10-12], e.g., as organic field effect transistors (OFETs) [13], in organic lightemitting diodes (OLEDs) [14,15] and in dye-sensitized solar cells (DSSCs) [16]. Particularly, MCR accesses to fluorophores [17] by virtue of transition metal catalysis [18] or via the intermediacy of alkynoyl derivatives [19] aroused growing attention over the past years. Thus, the transition metal catalyzed multicomponent approach [20] furnishes reactive electrophilic building blocks, such as alkynones $\mathbf{1}$ [21-23], propiolic acid esters 2, and alkyne-1,2-diones 3, set the stage for numerous follow-up transformations (Scheme 1). Hence, this review flashlights recent progresses in the years 2016 to 2021 and updates our previous overview [24] on the synthesis of heterocycles by virtue of the catalytic generation alkynoyl intermediates.<smiles>[R]C#CC([R])=O</smiles>

1 Alkynones<smiles>[R]C#CC([R20])=O</smiles>

2 Alkyl propiolates<smiles>[R]C#CC(=O)C([R])=O</smiles>

3

Alkyne-1,2-diones

Scheme 1. Alkynones, alkyl propiolates, and alkyne-1,2-diones as pivotal alkynoyl derivatives accessible by catalytic transformations.

After a concise introduction to our catalytic alkynylation-based concept for the generation alkynoyl specimen and recently developed accesses by others (Section 2) the review is rather structured by one-pot syntheses of nitrogen (Section 3) and oxygen containing heterocycles (Section 4) and thiophenes (Section 5) in a multicomponent fashion than by the mode of catalytic ynoyl generation.

\section{Alkynone, Alkyl Propiolate, and Alkyne-1,2-Dione Formation by Catalytic Processes}

Over twenty years, we have disclosed a broad collection of complementary syntheses of alkynones based upon Sonogashira alkynylation, which also have been employed by others for one-pot syntheses of heterocycles. The immense explorative potential of these versatile three-carbon building blocks is particularly illustrated in the preparation of nitrogen, oxygen, and sulfur containing five- to seven-membered heterocycles [25]. Here, six complementary methods provide powerful routes to alkynones $\mathbf{1}$, which form the starting point of diversity-oriented syntheses (Scheme 2).

Improving the reaction conditions of alkynes and acid chlorides in $\mathrm{Pd}-\mathrm{Cu}$-catalyzed alkynylations [26-28] is achieved by restricting the auxiliary base to one stoichiometrically necessary equivalent at the stage of the modified Sonogashira cross-coupling I [29,30]. Omitting copper as a cocatalyst circumvented the inherent alkyne dimerization effectively upon employing an electron-rich palladium complex in variant II [31]. Furthermore, this method allows concatenating single reaction steps to one-pot sequences since the solvent can be readily varied. Toluene, 1,4-dioxane, acetonitrile and dichloromethane work equally well as solvents, and in particular, acetonitrile and dichloromethane are very favorable for subsequent Michael additions. Another possibility to significantly broaden the substrate scope was established by employing oxalyl chloride for en route activation of carboxylic acids III [32], tolerating $N$-heterocyclic substituents and electronrich $\pi$-nucleophiles IV [33].

While the previous approaches are directly founded on the coupling of monosubstituted alkynes a more direct pathway represents the coupling of aryl halides and ethynylmagnesium bromide and then acid chlorides as presented in Kumada-Sonogashira sequence $\mathbf{V}$ [34]. Thereby, the unsymmetrically substituted alkynones are easily accessible with a broadened substrate scope. Aryl iodides are preferentially utilized as substrates in the carbonylative cross-coupling Sonogashira reaction VI [35-37]. However, the intro- 
duced aryl moiety is regiospecifically ligated to the alkynone's carbonyl group in this complementary synthetic route to alkynones.

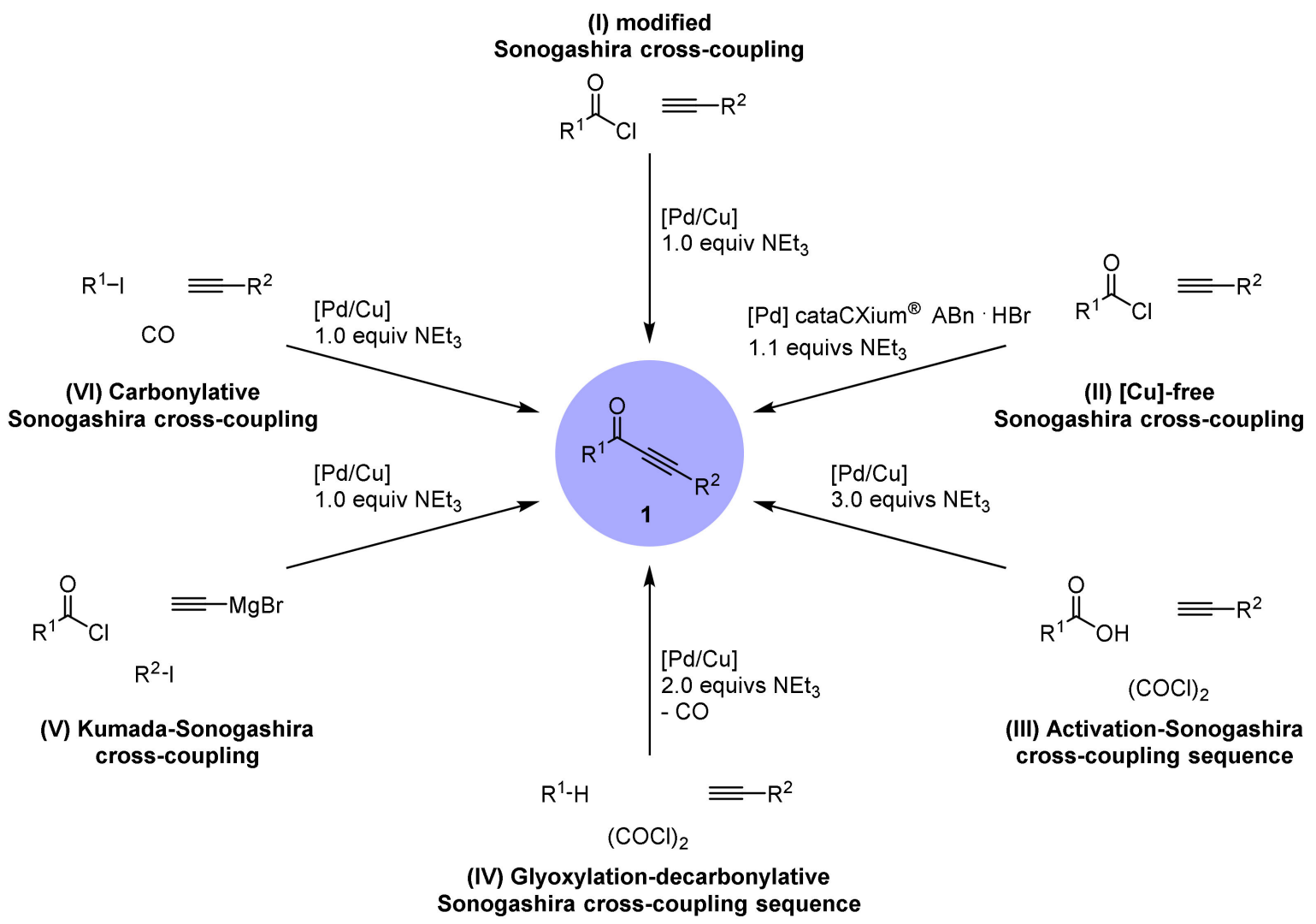

Scheme 2. Six Sonogashira alkynylation accesses to alkynone building blocks $\mathbf{1}$.

Zeng and coauthors dispensed a different approach utilizing Sonogashira coupling of $\mathrm{N}$-acylsaccharins $\mathbf{4}$ and alkynes $\mathbf{5}$ followed by a selective triethylamine mediated C-N bond cleavage. This palladium-catalyzed sequence retains from high catalyst loadings and from copper complexes enabling a broad substituent pattern for 29 examples embedding electron-rich and electron-poor (hetero)aryls, allyl and alkyl groups in good to excellent yields (Scheme 3) [38].

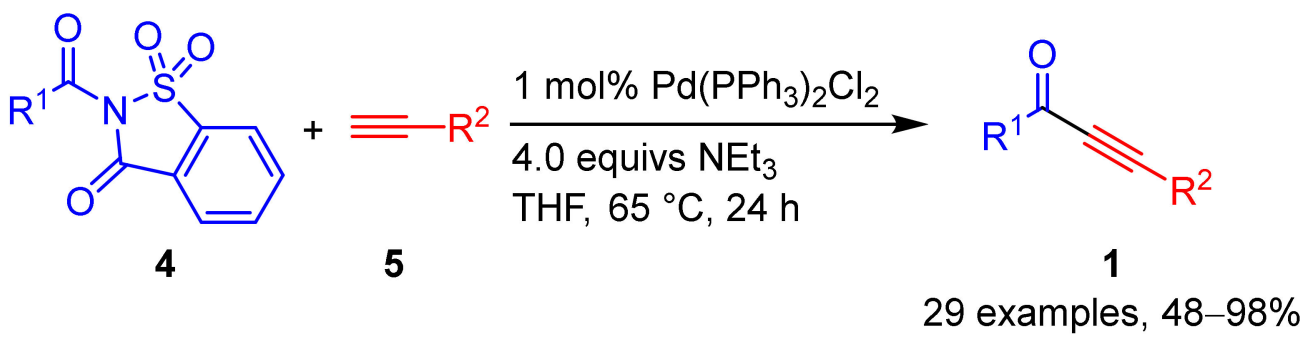

Scheme 3. Palladium-catalyzed ynone synthesis via $N$-acylsaccharin substrates 4 .

The straightforward Sonogashira coupling of aryl iodides 6 with ethyl propiolate (7) provides 12 examples of aryl propiolates 2 with multi-faceted substituents in up to $97 \%$ yield (Scheme 4). By applicating a syringe pump, this access compensated the inherent propensity of ethyl propiolate to undergo oligomerization under basic conditions as well as the reduced alkyne reactivity [39].

Palladium nanoparticle-catalyzed alkynylation of acyl chlorides are vivaciously developing and offer copper-free and aerobic conditions [40] as well as mild conditions without 
heating likewise [41,42]. The efficiency of the nanoparticle-based catalysts is additionally underlined by four to six recycling cycles with mostly excellent yields.

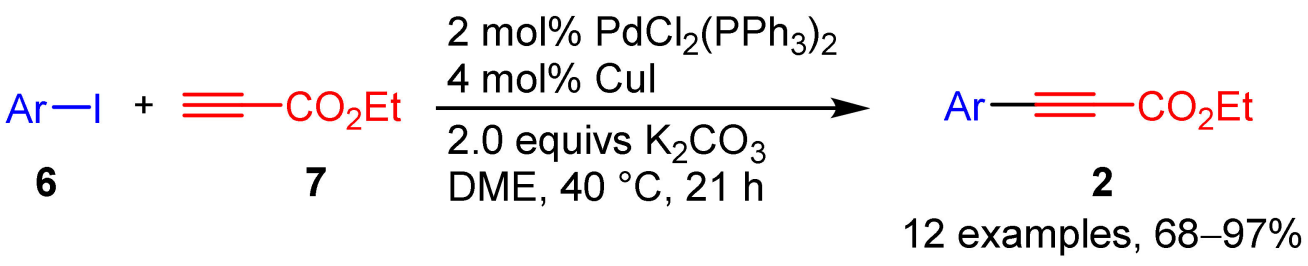

Scheme 4. 3-Aryl propiolates 2 by Sonogashira coupling of aryl iodides 6 and ethyl propiolate (7).

Guo reported the synthesis of structurally related ynediones 3 under an oxygen atmosphere. Starting from terminal alkynes 5 and $\alpha$-carbonyl aldehydes $\mathbf{8}$, this coppercatalyzed synthesis furnished 22 examples in 42 to $94 \%$ yield (Scheme 5) [43].<smiles>O=CC(=O)c1cc[R1]cc1</smiles>

8

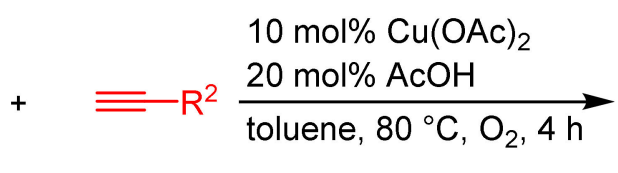

5<smiles>[R]C#CC(=O)C(=O)c1cc[R1]cc1</smiles>

22 examples, $42-94 \%$

Scheme 5. Copper-catalyzed oxidative coupling of $\alpha$-carbonyl aldehydes 8 and alkynes $\mathbf{5}$ to ynediones 3 under aerobic conditions.

\section{Nitrogen Containing Heterocycles by Multicomponent Syntheses}

This chapter summarizes recent multicomponent syntheses of pyrazolines, pyrazoles, triazoles, indolones, pyridines, pyrimidines, isoquinolines, and quinoxalines based upon the catalytic entry to alkynoyl intermediates.

\subsection{Pyrazolines}

Pyrazoles and pyrazolines are five-membered heterocycles containing two nitrogen atoms in the ring. These systems, accessible via alkynones, are among the most prominent ring systems and particularly versatile and powerful targets for applications in the life and materials sciences [44-46]. Employing oxalyl chloride in copper-catalyzed alkynylations alkynediones become accessible for subsequent multicomponent reactions. Consequently, 1,5-diacyl-5-hydroxypyrazolines $\mathbf{1 1}$ are generated employing a consecutive sequence of activation of glyoxylic acids 9, alkynylation and cyclization with acylhydrazines 10. Görgen et al. isolated 17 examples with 3 different points of variation in mostly good yields bearing different (hetero)aryl and alkyl substituents (Scheme 6) [47].

\subsection{Pyrazoles}

In two complementary routes functional pyrazoles $\mathbf{1 3}$ and pyrimidines $\mathbf{1 5}$ were accessed by four-component reactions in 35-79\% yield. Therefore, the authors established a sequentially Pd-catalyzed alkynone generation followed by cyclocondensation with either hydrazines 12 or benzamidinium chlorides 14 to obtain the heterocycles (Scheme 7) [48]. The resulting scaffolds, in particular, 3,5-diarylpyrazoles with donor-acceptor substitution pattern, are photophysically interesting due to huge emission solvatochromicity. In addition, the methodology was extended to a symmetrical dipyrazole, employing 1,4diidobenzene in a pseudo-seven-component synthesis. In contrast to the microwaveassisted cyclocondensation of pyrazoles, six examples of pyrimidines were synthesized under conductive heating in $42-51 \%$. 


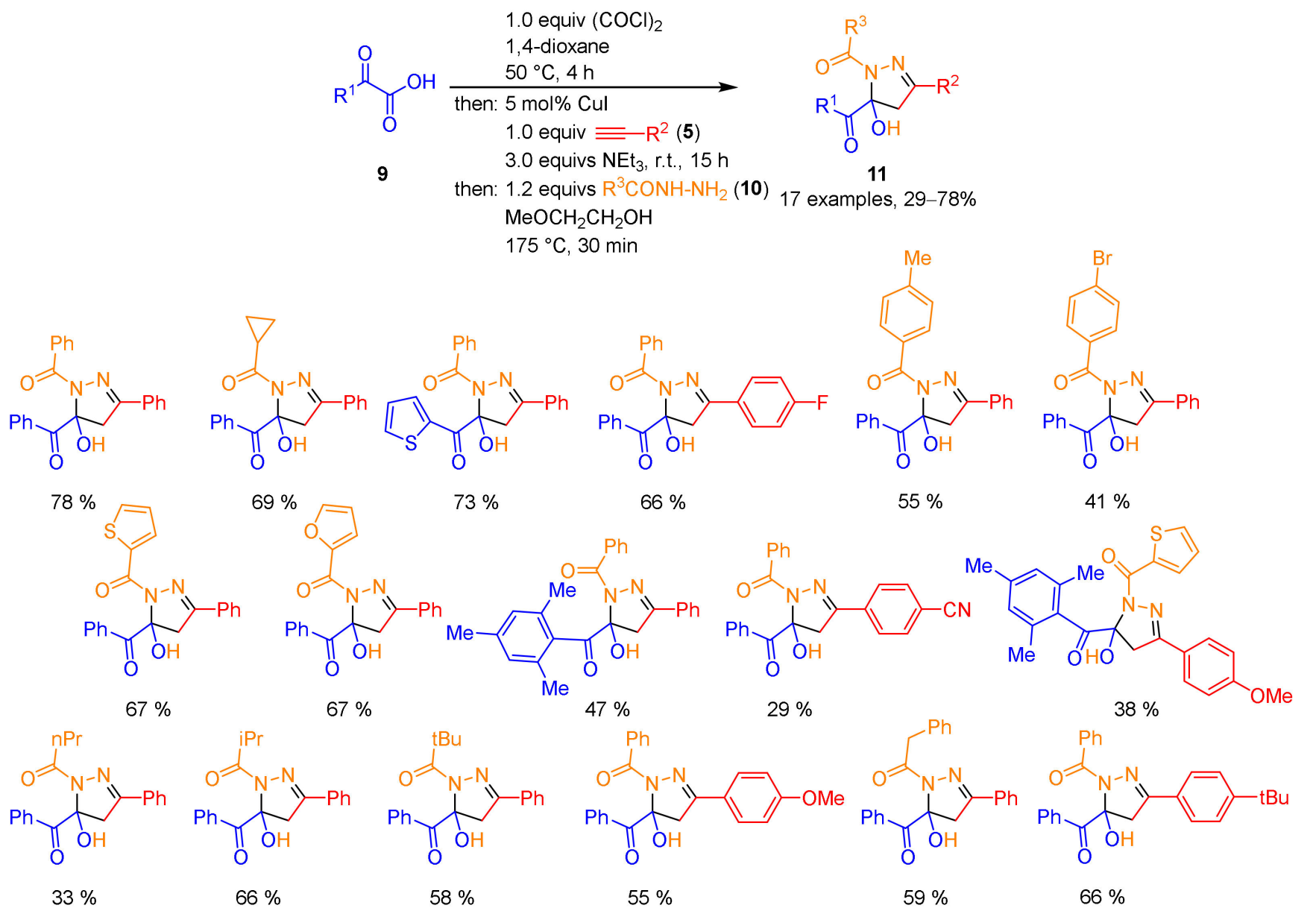

Scheme 6. Consecutive three-component activation-alkynylation-cyclocondensation synthesis of 1,5-diacyl-5-hydroxypyrazolines 11.

Another approach to pyrazoles starts with the coupling of aryliodides and ethyl propiolates [49]. Whilst the general cross-coupling of aryl halides 6 and terminal alkynes is well established, the direct alkynylation with ethyl propiolate (7) as a substrate requires slow addition (syringe pump) due to its volatility and inherent base sensitivity leading to oligomerization of this versatile building block. The concluding cyclocondensation step with hydrazines 12 gives access to 17 3-hydroxy pyrazoles 16 in $48-95 \%$ of the yield in a three-component one-pot fashion (Scheme 8) [50]. Usually, these scaffolds are synthesized by cyclocondensation of hydrazines and $\beta$-keto esters. However, due to their higher electrophilicity 3-aryl propiolates 2 are favorable synthetic equivalents of 1,3-diketones suspending the carbonyl group activation. These advantages result in a broad substrate scope of aryl groups bearing electron-poor to electron-rich (hetero)aryls and underline in combination with methyl, alkyl, and benzyl substituted hydrazines the versatility of this method.

The alternative building block (triisopropylsilyl)butadiyne 18 on the pathway to synthesize pyrazoles is presented by Niesobski and coauthors. Starting from acid chlorides 17 and this four-carbon building block 15, examples of 4-pyrazolyl-1,2,3-triazoles 20 with versatile substituents were obtained in a consecutive four-component one-pot fashion and $35-60 \%$ yields [51]. This methodology also combines Sonogashira coupling and MedalSharpless copper-click reaction in a sequentially $\mathrm{Pd}-\mathrm{Cu}$-catalyzed process with a single catalyst source (Scheme 9). 


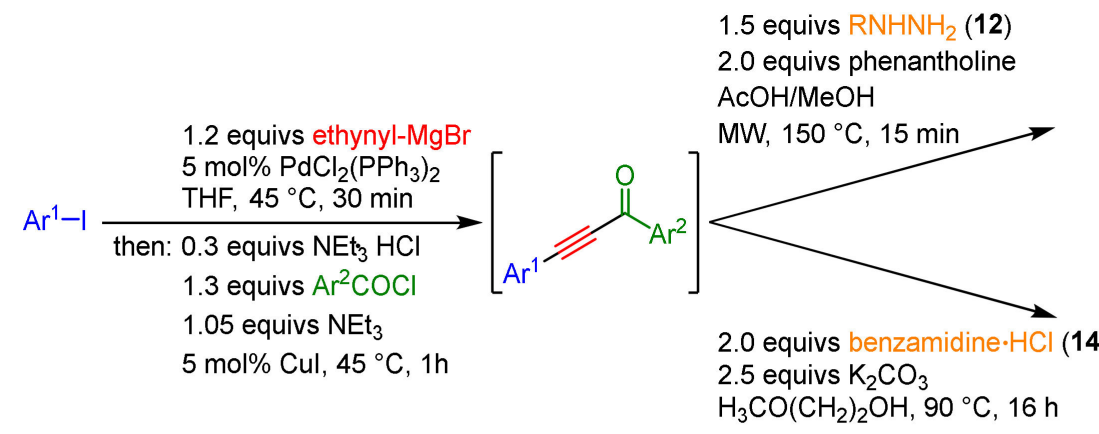

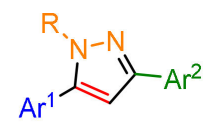

13

17 examples, $35-79 \%$

${ }_{A r}{ }^{2}$

2.5 equivs $\mathrm{K}_{2} \mathrm{CO}_{3}$

$\mathrm{H}_{3} \mathrm{CO}\left(\mathrm{CH}_{2}\right)_{2} \mathrm{OH}, 90^{\circ} \mathrm{C}, 16 \mathrm{~h}$

6 examples, $42-51 \%$<smiles>COc1ccc(-c2cc(-c3ccccc3)nn2-c2ccccc2)cc1</smiles><smiles>Cc1ccc(-c2cc(-c3ccc(C)cc3)n(C)n2)cc1</smiles>

$47 \%$<smiles>Cn1nc(-c2ccccc2)cc1-c1ccc(OC(F)(F)F)cc1</smiles>

$59 \%$

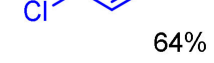<smiles>CCCCCCN(C)C</smiles>

$77 \%$

(1)

$58 \%$<smiles>Cn1nc(-c2ccc(-c3cc(-c4ccc(C(F)(F)F)cc4)nn3C)cc2)cc1-c1ccccc1</smiles>

$68 \%$<smiles>Cc1ccc(-c2cc(-c3ccccc3)n(C)n2)cc1</smiles><smiles>Cn1nc(-c2ccc(-c3cc(-c4ccccc4)n(C)n3)cc2)cc1-c1ccccc1</smiles><smiles>COc1ccc(-c2cc(-c3ccccc3)n(C)n2)cc1</smiles>

$79 \%$<smiles>C1CCC1</smiles><smiles>Cc1cc(-c2ccc(C(F)(F)F)cc2)nn1C</smiles><smiles>CN(C)c1ccc(-c2cc(-c3ccccc3)nn2C)cc1</smiles><smiles>COc1ccc(-c2cc(-c3ccccc3)nc(-c3ccccc3)n2)cc1</smiles>

$58 \%$<smiles>CC(C)(C)OC(C)(C)O</smiles>

$64 \%$<smiles>Clc1ccc(-c2cc(-c3ccccc3)nc(-c3ccccc3)n2)cc1</smiles>

$60 \%$<smiles>Clc1cccc(-c2cc(-c3ccc(Br)cc3)nc(-c3ccccc3)n2)c1</smiles><smiles>Cc1ccc(-c2cc(-c3ccccc3)nc(-c3ccccc3)n2)cc1</smiles>

$43 \%$<smiles>Cc1ccc(-c2cc(-c3ccc4ccccc4c3)nc(-c3ccccc3)n2)cc1</smiles>

$46 \%$

Scheme 7. Consecutive four-component coupling-cyclocondensation syntheses of pyrazoles and pyrimidines.

As previously mentioned, palladium catalysts furnish alkynones for entering ynone-based multicomponent reactions. A promising approach utilizing 3-(2-aminoethylamino)propylfunctionalized MCM-41-immobilized palladium(II) complex [MCM-41-2N-Pd(OAc) 2 ] has been followed by Cai and coworkers. In addition to the palladium catalyst, CuI catalyzes the alkynalation of acid chlorides $\mathbf{1 7}$ with terminal alkynes $\mathbf{5}$ to give ynones. In a subsequent cyclocondensation of hydrazines 27 pyrazoles 21 with a broad substituent scope were synthesized in moderate-to-good yields in this one-pot process (Scheme 10) [52]. 
The authors found a higher catalytic activity of the immobilized palladium catalyst compared to $\mathrm{PdCl}_{2}\left(\mathrm{PPh}_{3}\right)_{2}$. Furthermore, the catalyst was recovered and reused for at least ten times without significant depression of activity.

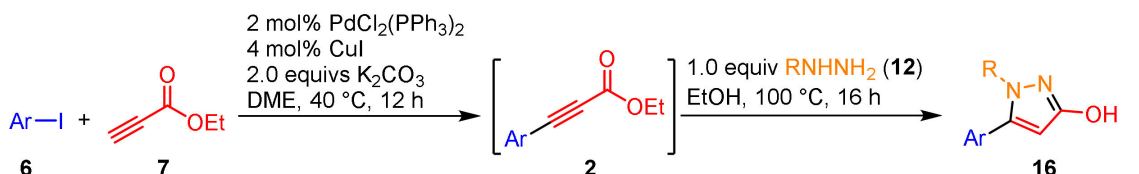

$6 \quad 7$ 17 examples, 48-95\%<smiles>Oc1cc(-c2ccccc2)n[nH]1</smiles>

$80 \%$<smiles>Nc1ccc(-c2cc(O)nn2-c2ccccc2)cc1</smiles>

$78 \%$<smiles>COc1ccc(-c2cc(O)nn2N)cc1</smiles>

$86 \%$<smiles></smiles>

$95 \%$<smiles>Cc1ccc(-c2cc(O)nn2C)cc1</smiles><smiles>COc1cc(-c2ccncc2)nn1N</smiles>

$67 \%$<smiles>Nc1nn(-c2ccccc2-c2cc(O)nn2N)cc1-c1ccc(Br)cc1</smiles>

$71 \%$

$87 \%$<smiles>Nn1nc(O)cc1-c1ccccc1Cl</smiles>

$63 \%$<smiles>Nn1nc(O)cc1-c1ccc(F)cc1</smiles>

$79 \%$<smiles>[N+]=[N+]=NC(O)=Cc1ccc(Cl)cc1</smiles>

$74 \%$<smiles>Cn1nc(O)cc1-c1ccc(C(F)(F)F)cc1</smiles><smiles>CC(C)(C)O[Na]</smiles><smiles>CC(C)(C)OC(=O)c1ccccc1-c1cc(O)nn1Cc1ccccc1</smiles><smiles>Oc1cc(-c2ccccc2)n(Cc2ccccc2F)n1</smiles><smiles>CC(C)(C)[Na]</smiles><smiles>CCCn1nc(O)cc1-c1ccccc1</smiles>

Scheme 8. One-pot alkynylation-cyclocondensation access to 3-hydroxy pyrazoles 16.
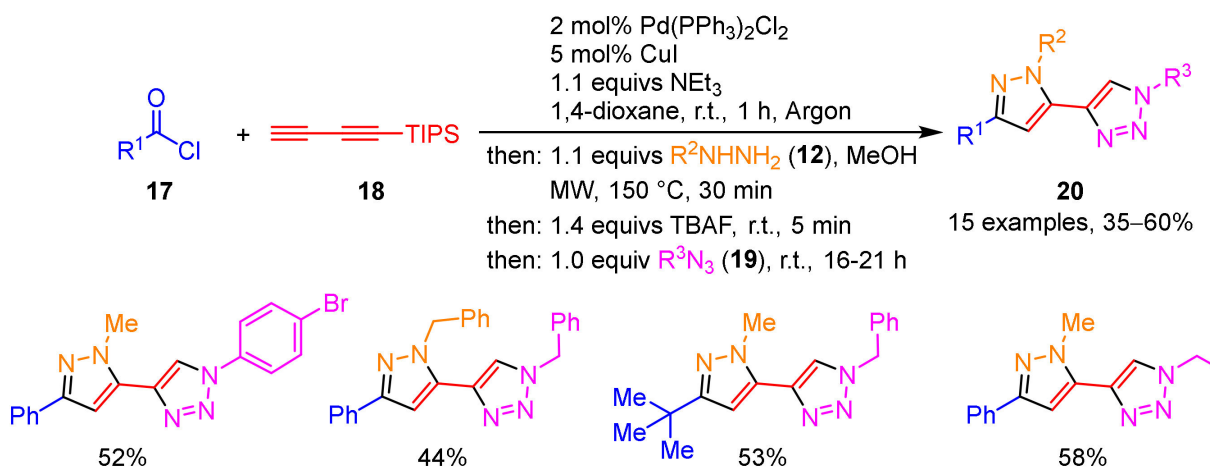<smiles>Cc1ccc(Cn2cc(-c3cc(-c4ccccc4)nn3C)nn2)cc1</smiles>

$58 \%$<smiles></smiles>

$57 \%$<smiles></smiles>

$60 \%$<smiles>Cn1nc(-c2cccs2)cc1-c1cn(Cc2ccccc2)nn1</smiles>

$59 \%$<smiles></smiles>

$60 \%$<smiles>COc1ccc(-c2cc(-c3cn(Cc4ccccc4)nn3)n(C)n2)cc1</smiles><smiles>Cn1nc(-c2ccc(Cl)cc2)cc1-c1cn(Cc2ccccc2)nn1</smiles><smiles>CC(C)c1cc(-c2cn(-c3ccccc3)nn2)n(C)n1</smiles>

$35 \%$<smiles>Cn1nc(-c2ccccc2)cc1-c1cn(CCc2ccccc2)nn1</smiles>

$48 \%$<smiles>CC(=O)Cn1cc(-c2cc(-c3ccccc3)n[nH]2)nn1</smiles>

$49 \%$<smiles>COc1ccc(-n2cc(-c3cc(-c4ccccc4)nn3C)nn2)cc1</smiles>

$54 \%$

Scheme 9. Consecutive four-component formation of 4-pyrazolyl-1,2,3-triazoles 20. 


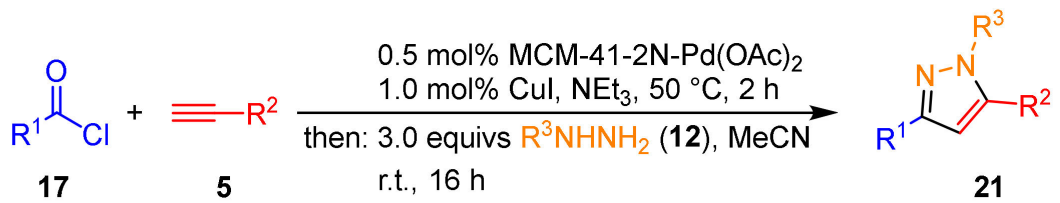

27 examples, $25-88 \%$<smiles></smiles><smiles>COc1ccc(-c2cc(-c3ccccc3)n[nH]2)cc1</smiles>
$88 \%$ $83 \%$

$80 \%$ $77 \%$<smiles>COc1ccc(-c2cc(-c3ccc(OC)cc3)[nH]n2)cc1</smiles>

$74 \%$

$85 \%$

$81 \%$

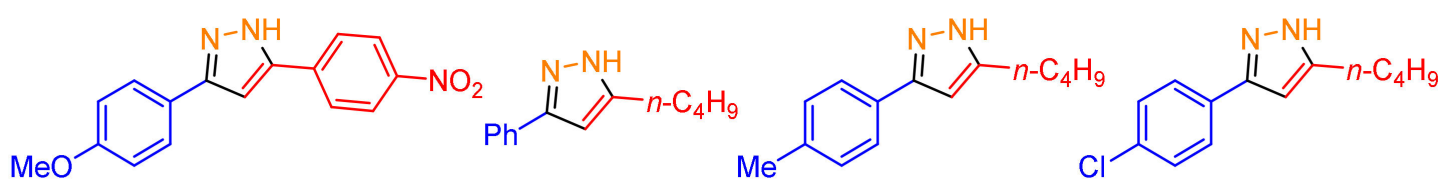

$78 \% \quad 60 \%$

$56 \%$

$54 \%$

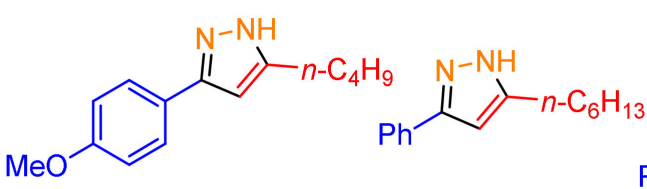

$61 \%$

$25 \%$<smiles>OCCn1nc(-c2ccccc2)cc1-c1ccccc1</smiles>

$79 \%$<smiles>Cc1ccc(-c2cc(-c3ccccc3)n(CCO)n2)cc1</smiles>

$22 \%$<smiles>OCCn1nc(-c2ccc(Cl)cc2)cc1-c1ccccc1</smiles><smiles>COc1ccc(-c2cc(-c3ccco3)n(CCO)n2)cc1</smiles>

Scheme 10. Consecutive one-pot alkynylation-cyclocondensation formation of pyrazoles 21.

\subsection{Triazoles}

1,4-Disubstituted 1,2,3-triazoles by Cu-catalyzed alkyne-azide cycloaddition (CuAAC) [53] have found widespread application ranging from drug discovery [54] to lead finding [55] in medicinal chemistry [56], in bioorganic [57,58] as well as in materials chemistry [59-64].

Hayeebueraheng and coauthors described the multicomponent synthesis of 2-(1,2,3triazolyl)benzamides 23 starting from 2-iodobenzamides 22 , sodium azide, and terminal alkynes 5 leading to 20 examples in 60-96\% yield (Scheme 11) [65]. This copper(I)-catalyzed one-step cycloaddition only proceeds in the absence of a base and proceeds quite rapidly. 
The diversity of the process was underlined by successfully employing electron donating and withdrawing groups 2-iodobenzamides and aromatic and aliphatic terminal alkynes.

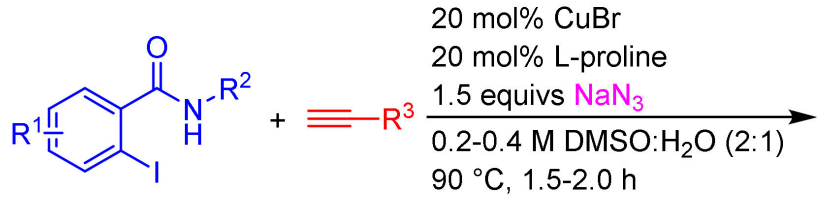

22
5<smiles>[R]NC(=O)c1cc[R1]cc1-n1cc([R])nn1</smiles>

23

20 examples, $60-96 \%$<smiles>O=C(NCc1ccccc1)c1ccccc1-n1cc(-c2ccccc2)nn1</smiles>

$82 \%$<smiles>COc1cc(C(=O)NCc2ccccc2)c(-n2cc(-c3ccccc3)nn2)cc1OC</smiles>

$60 \%$<smiles>COc1ccc(-n2cc(-c3ccccc3)nn2)c(C(=O)NCc2ccccc2)c1</smiles>

$90 \%$<smiles>COc1ccc(C(=O)NCc2ccccc2)c(-n2cc(-c3ccccc3)nn2)c1</smiles>

$93 \%$<smiles>CNC(=O)c1ccc(C(=O)NC)c(-n2cc(-c3ccccc3)nn2)c1</smiles><smiles>CNC(=O)c1ccc(Cl)cc1-n1cc(-c2ccccc2)nn1</smiles><smiles>O=C(NCc1ccccc1)c1cc(Br)ccc1-n1cc(-c2ccccc2)nn1</smiles><smiles>Cc1cccc(C(=O)NCc2ccccc2)c1-n1cc(-c2ccccc2)nn1</smiles>

$92 \%$ $70 \%$<smiles>O=C(NC1CCCCC1)c1ccccc1-n1cc(-c2ccccc2)nn1</smiles><smiles>CC(C)(C)OC(=O)NCCNC(=O)c1ccccc1-n1cc(-c2ccccc2)nn1</smiles>

$90 \%$<smiles>NC(=O)c1ccccc1-n1cc(-c2ccccc2)nn1</smiles><smiles>NC(=O)c1ccccc1-n1cc(-c2cccs2)nn1</smiles>

$96 \%$<smiles>O=C(NCc1ccccc1)c1ccccc1-n1cc(-c2ccc(Br)cc2)nn1</smiles>

$72 \%$

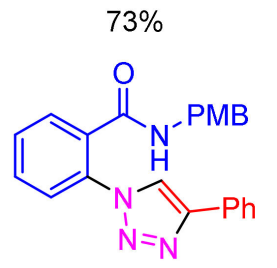

$81 \%$<smiles>NC(=O)c1ccccc1-n1cc(-c2ccccn2)nn1</smiles>

$93 \%$<smiles>COc1ccc(-c2cn(-c3ccccc3C(=O)NCc3ccccc3)nn2)cc1</smiles>

$82 \%$<smiles>O=C(Nc1ccccc1)c1ccccc1-n1cc(-c2ccccc2)nn1</smiles>

$68 \%$<smiles>O=C(NCc1ccccc1)c1ccccc1-n1cc(C2CC2)nn1</smiles>

$71 \%$<smiles>O=C(NCc1ccccc1)c1ccccc1-n1cc(-c2ccc([N+](=O)[O-])cc2)nn1</smiles>

$95 \%$

Scheme 11. Consecutive azidation-alkyne-azide cycloaddition formation of 2-(1,2,3-triazolyl) benzamides 23 .

An alternative three-carbon building block was established by Schreiner and coauthors, implementing propargyl bromide (24) in different one-pot fashion syntheses. In a four-component synthesis, 15 examples of 1,2,3-triazolylmethylarylpropiolates were obtained in moderate to good yields resulting from a sequentially $\mathrm{Cu}$-catalyzed alkyne carboxylation-propargylation and terminating $\mathrm{CuAAC}$. Utilizing the internal triple bond 
by concatenating a concluding Michael addition, a consecutive five-component synthesis of 1,2,3-triazolylmethyl 3-amino 3-arylacrylates 25 was conceived (Scheme 12). The process benefits from mild reaction conditions enabling two sequentially $\mathrm{Cu}$-catalyzed steps with a single catalyst source, resulting in four new formed bonds in a moderate yield [66].

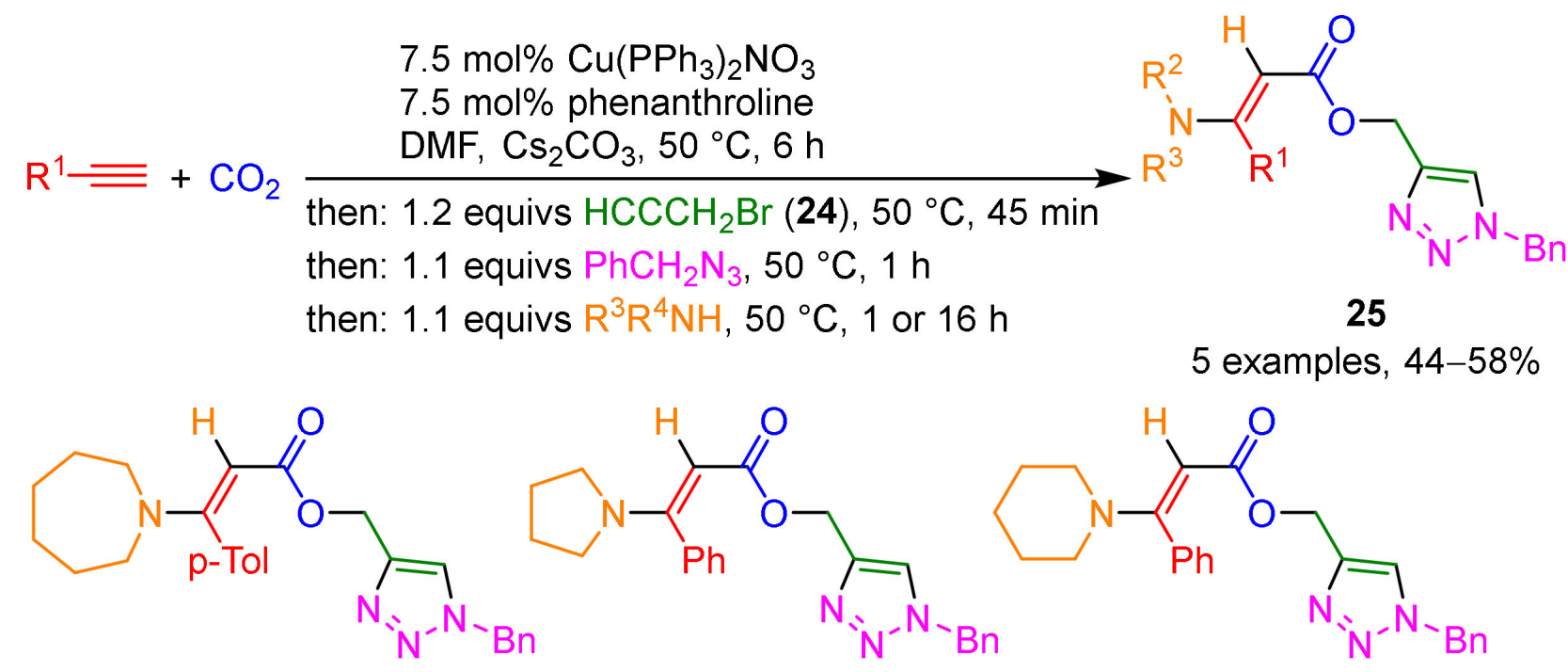

$45 \%$

$58 \%$

$44 \%$

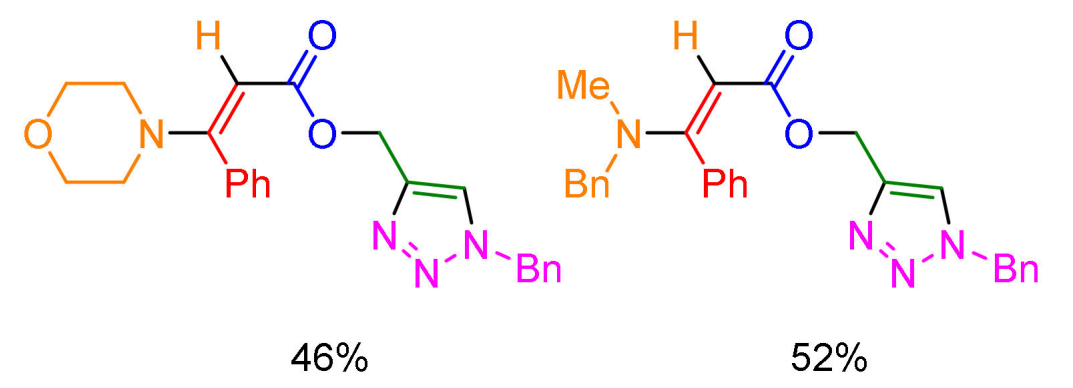

Scheme 12. 1,2,3-Triazolylmethyl 3-amino 3-arylacrylates 25 by consecutive five-component carboxylation-propargylation-CuAAC-Michael addition sequences.

\subsection{Indolones}

Spirocyclic oxindoles and indolones have received considerable interest due to their biological properties [67-69]. A promising entrance to rigid, emissive spiro-indolones has been described by Schönhaber and coauthors. Starting with terminal alkynes $\mathbf{5}$ and $\mathrm{N}$-halophenylalkynylamides $\mathbf{2 6}$ heterocyclic propynylidene indolones $\mathbf{2 7}$ can be obtained in a one-pot fashion with an insertion-alkynylation sequence. Having three different points of variation for the formation of 24 solid-state luminescent propynylidene indolones 27 in moderate-to-excellent yields, the domino synthesis proved to be a straightforward and universal methodology (Scheme 13) [70].

The concept of the domino synthesis of propynylidene indolones led to several consecutive follow-up syntheses. In a 3-component synthesis, 12 examples of 3-piperazinyl propenylidene indolones 28 were obtained in poor-to-excellent yields with a reasonably broad substitution pattern and in vastly short reaction times. Therefore, the solvent system was improved to dichloromethane and acetonitrile at elevated temperatures for the combined sequence and allowing the introduction of electronically diverse substituents on the alkynyl aryl moieties (Scheme 14) [71]. 


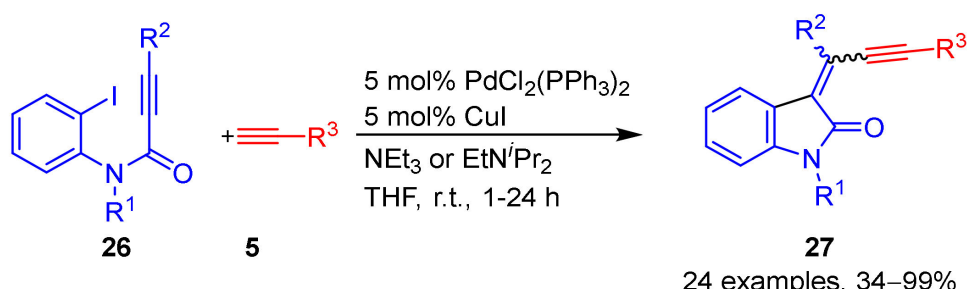<smiles>COc1ccc(C#C[C@@H](c2ccccc2)c2c([C@H](C#Cc3ccc(Cl)cc3)c3ccccc3)c3ccccc3n2C)cc1</smiles>

$99 \%(E / Z=60: 40)$

$98 \%(E / Z=80: 20)$

$95 \%(E / Z=75: 25)$

$99 \%(E / Z=0: 100)$

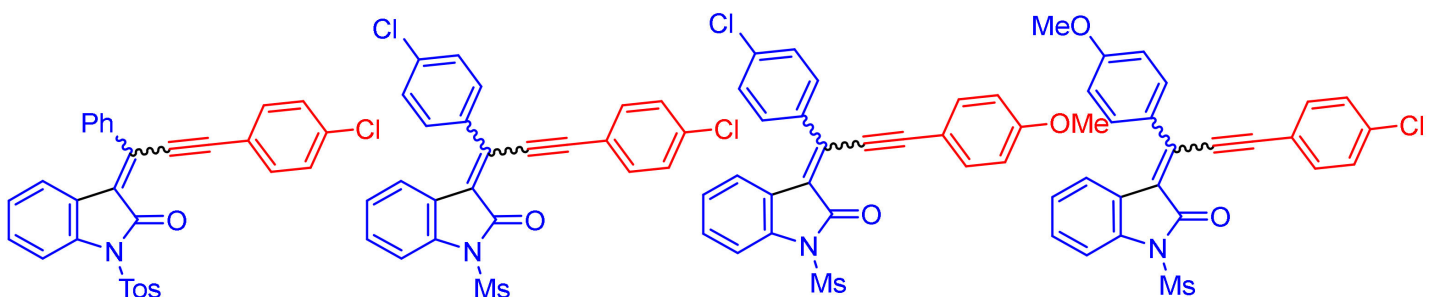

$90 \%(E / Z=33: 67)$

$99 \%(E / Z=50: 50)$

$99 \%(E / Z=67: 33)$

$99 \%(E / Z=40: 60)$

$\mathrm{MeO}$

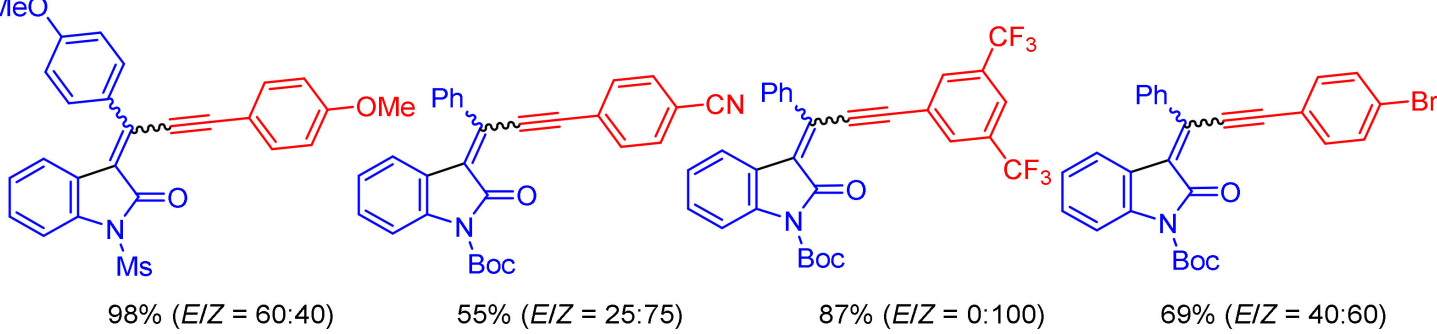<smiles></smiles>

$96 \%(E / Z=62: 38)$

$34 \%(E / Z=97: 3)$

$75 \%(E / Z=88: 12)$

$55 \%(E / Z=50: 50)$<smiles>CCCCNc1ccc(C#C[C@@H](c2ccccc2)C2C(=O)N(C(=O)OC(C)(C)C)c3ccccc32)cc1</smiles>

$53 \%(E / Z=33: 66)$

$68 \%(E / Z=85: 15)$

$44 \%(E / Z=40: 60)$

$50 \%(E / Z=49: 51)$<smiles></smiles>

$52 \%(E / Z=44: 56) \quad 79 \%(E / Z=100: 0)$

$47 \%(E / Z=100: 0)$

$57 \%(E / Z=0: 100)$

Scheme 13. One-pot insertion-alkynylation synthesis of spiro-indolones 27. 
Based on the same principle, an expansion of 3-piperazinyl propenylidene indolone merocyanines was pursued by superseding boc protected piperazine with distinct substituted analogues to obtain merocyanine-triarylamine bichromophores 30 . The onepot three-component synthesis started from ortho-bromo anilidines 29 forming the indolone scaffold and phenylacetylene as alkyne component, before the piperazine analogue was added. Four propenylidene indolone bichromophores 30 examples in poor-to-good yields were furnished by the consecutive insertion-alkynylation-Michael addition sequence (Scheme 15) [72].<smiles>[R]c1ccc(C#CC(=O)N([R1])c2ccccc2Br)cc1</smiles>
$\mathrm{R}^{1}$

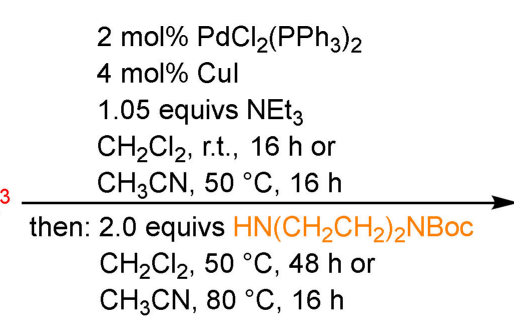

$\mathrm{CH}_{3} \mathrm{CN}, 80^{\circ} \mathrm{C}, 16 \mathrm{~h}$

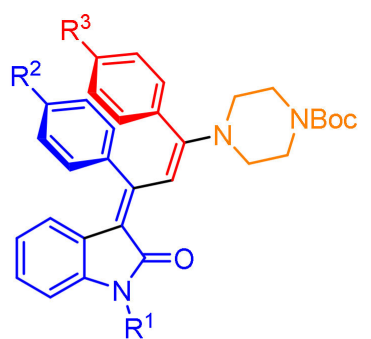

28

12 examples, 10-95\% $\mathrm{MeO}$<smiles>COC(=O)N1CCN(c2cc(=C3C(=O)N([N+](=O)[O-])c4ccccc43)c3cccc4cccc2c43)CC1</smiles>

$55 \%$ (in dichloromethane) $71 \%$ (in acetonitrile)

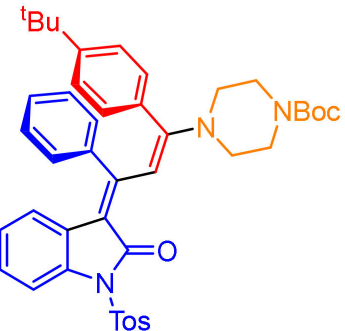
$50 \%$<smiles>CC(C)(C)OC(=O)N1CCN2C=C(C2=CC(=C2C(=O)N([13CH3])c3ccccc32)c2ccc(C(C)(C)C)cc2)c2ccccc21</smiles>
$35 \%$

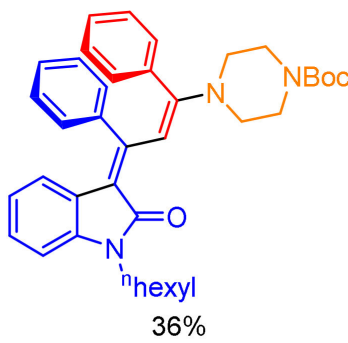<smiles>Cc1ccc2c(c1)C(=C1C(=O)N([13C]3CCCN(C(C)(C)C)CC3)c3ccccc31)C=C2c1ccccc1</smiles>
$57 \%$<smiles>Cc1ccc(C(C=C(c2ccccc2)N2CCN(C(=O)OC(C)(C)C)CC2)=C2C(=O)N([13CH3])c3ccccc32)cc1</smiles>
$32 \%$<smiles>CC(C)(C)OC(=O)N1CCN(C2=CC(=C3C(=O)N([13CH3])c4ccccc43)c3ccccc32)CC1</smiles>

$27 \%$ (in dichloromethane) $95 \%$ (in acetonitrile)<smiles></smiles>
$10 \%$<smiles>CC(C)(C)OC(=O)N1CCN(C2=CC(=C3C(=O)N([O+])c4ccccc43)c3ccc(Cl)cc32)CC1</smiles>

$54 \%$

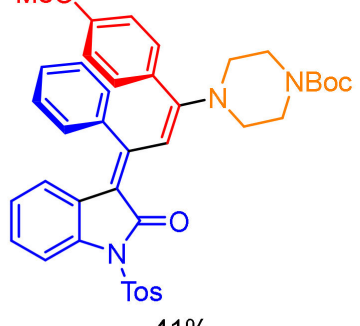
$41 \%$<smiles></smiles>
$17 \%$<smiles>CC(C)(C)OC(=O)N1CCN(C(=CC(=C2C(=O)N([13CH3])c3ccccc32)c2ccc(C#N)cc2)c2ccccc2)CC1</smiles>

Scheme 14. 3-Piperazinyl propenylidene indolone merocyanines 28 by consecutive three-component insertion-alkynylation-Michael addition sequence.

A further expanded sequence takes advantage of 1-(4-bromobenzyl)piperazine (31) in a modular strategy, enabling a Suzuki coupling as terminal step. Utilizing different aryl (pinacolato)boronates 32 four 3-piperazinyl propenylidene indolone bichromophores 33 were accessed in a consecutive four-component reaction in moderate-to-good yields (Scheme 16). Whilst an excess of carbonate and boronate was necessary for the Suzuki coupling, no further catalyst had to be added after the catalytic insertion-coupling step. 
Upon aggregation, the indolone bichromophores act as white light emissive systems which caused the dual emission of both chromophore units as a result of a partial energy transfer.<smiles>[R]N(C(=O)C#Cc1ccccc1)c1ccccc1Br</smiles>

29

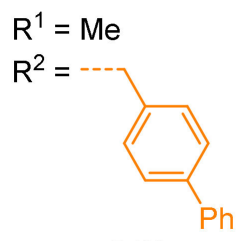

$64 \%$

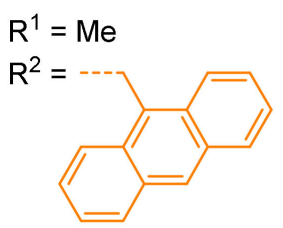

$69 \%$
$2 \mathrm{~mol} \% \mathrm{PdCl}_{2}\left(\mathrm{PPh}_{3}\right)_{2}$

$4 \mathrm{~mol} \% \mathrm{Cul}$

1.05 equivs $\mathrm{NEt}_{3}$

$\mathrm{CH}_{2} \mathrm{Cl}_{2}$, r.t. or

$\mathrm{CH}_{3} \mathrm{CN}, 50{ }^{\circ} \mathrm{C}, 15-20 \mathrm{~h}$

then: 2.0 equivs $\mathrm{HN}\left(\mathrm{CH}_{2} \mathrm{CH}_{2}\right)_{2} \mathrm{NR}^{2}$

$\mathrm{CH}_{2} \mathrm{Cl}_{2}, 50^{\circ} \mathrm{C}, 48 \mathrm{~h}$ or

$\mathrm{CH}_{3} \mathrm{CN}, 80^{\circ} \mathrm{C}, 16 \mathrm{~h}$

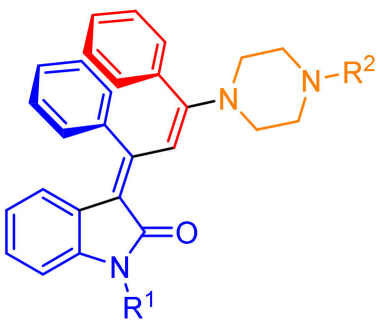

30

4 examples, $14-69 \%$

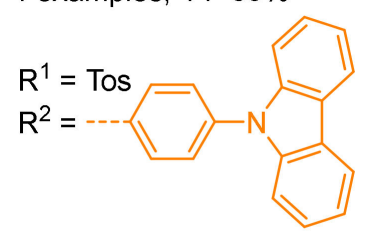

$40 \%$

Scheme 15. Consecutive three-component insertion-alkynylation-Michael addition synthesis of 3-piperazinyl propenylidene indolone bichromophores 30.<smiles>C#Cc1ccccc1C#CC(=O)N([14CH3])c1ccccc1Br</smiles>

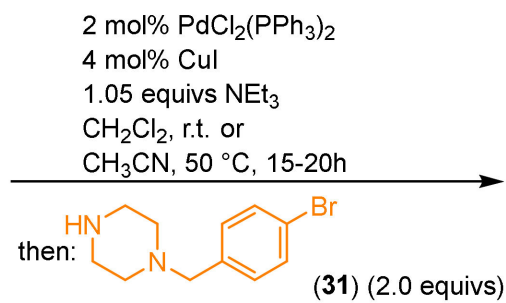

$\mathrm{CH}_{3} \mathrm{CN}, 80^{\circ} \mathrm{C}, 16 \mathrm{~h}$

then: 20 mol\% $\mathrm{PPh}_{3}, \mathrm{H}_{2} \mathrm{O}, 1,4$-dioxane

6.0 equivs $p-\mathrm{RC}_{6} \mathrm{H}_{4}$ Bpin (32)<smiles>O=C1C(=C2C=C(N3CCNCC3)c3ccccc3-c3ccccc32)c2ccccc2N1[13C](=O)[O-]</smiles>

$50 \%$

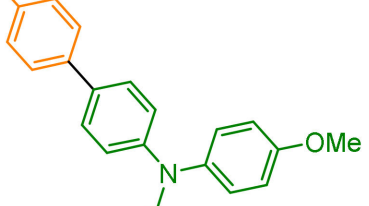<smiles></smiles>

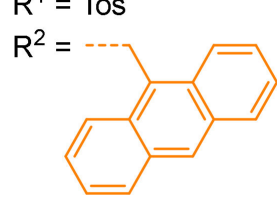

$14 \%$

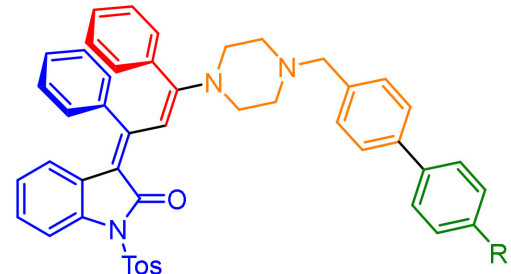

4 examples, $30-64 \%$

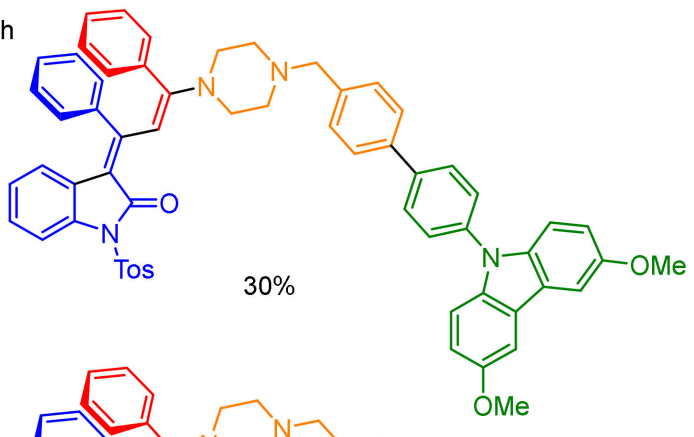

Scheme 16. Consecutive four-component insertion-alkynylation-Michael addition-Suzuki formation of 3-piperazinyl propenylidene indolone bichromophores 33. 
Pursuing a similar concept, Elsner and coauthors synthesized indolone-3-aminopropenylidene merocyanine dimers by employing bifunctional symmetric 1,4-phenylenedimethanamines 34 as amino components. When introducing different alkynes and secondary amino moieties, four unimolecular indolone dimers 35 were obtained in a pseudo-five-component synthesis in moderate yield (Scheme 17) [73]. Contrary to the previously described 3piperazinyl propenylidene indolone bichromophores, aggregation-induced emission is not prevalent for the symmetric structures. The authors gave a variable temperature NMR supported estimation of the rotational barriers of the terminal amino moieties.
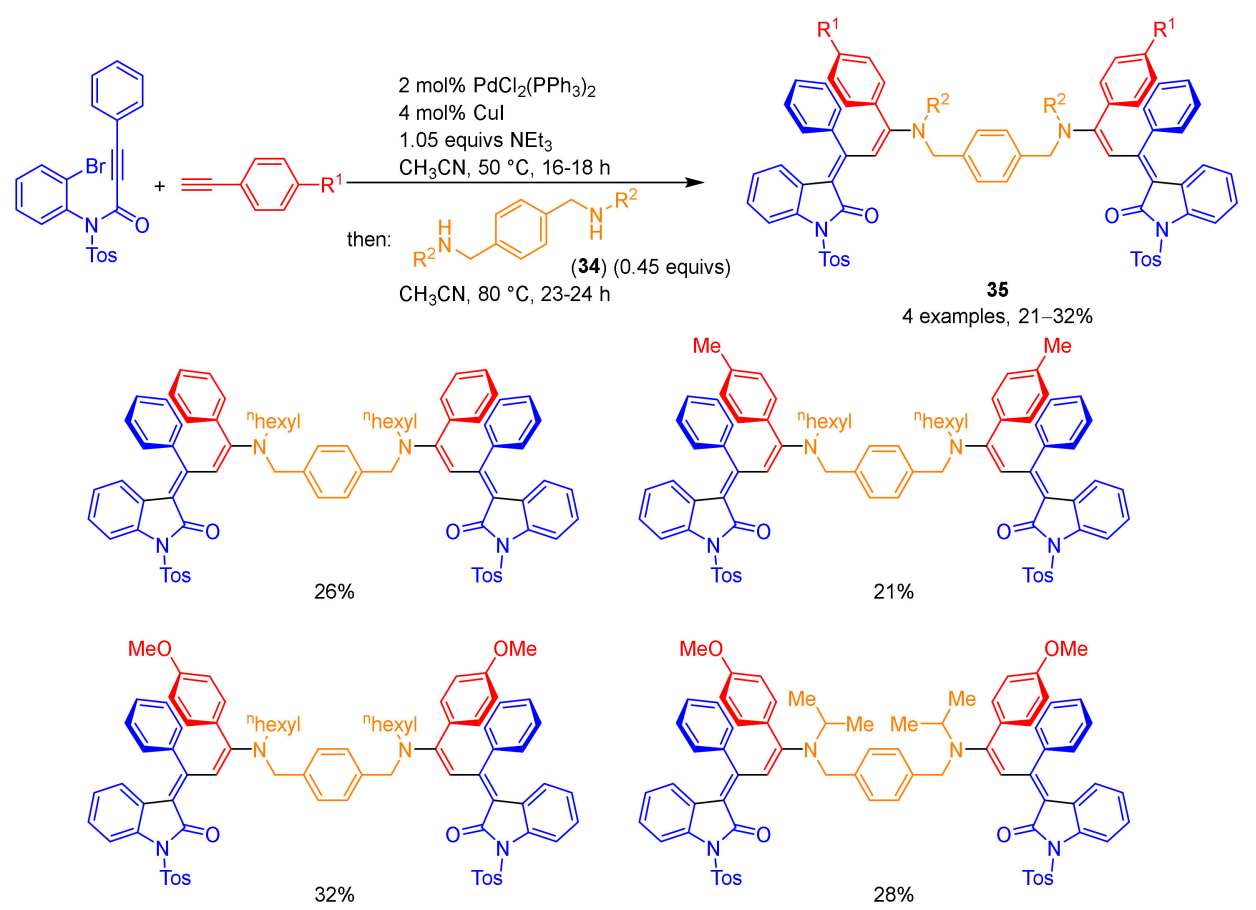

Scheme 17. Domino synthesis of indolone-3-minopropenylidene merocyanine dimers 35.

\subsection{Pyridines}

Pyridines and their fused derivatives are amongst evergreens in all fields of applications [74]. In the past few years, especially one-pot syntheses of six-membered heterocycles aroused increasing attention due to multifold properties $[75,76]$. Dohe and coauthors established a coupling-Bagley-Bohlmann-Rahtz synthesis of 15 tri- and tetrasubstituted pyridines 37 in poor-to-good yields, with an efficient yield per bond forming step of up to $82 \%$ (Scheme 18) [77]. The catalytically formed ynone was subsequently reacted in the same reaction vessel with ethyl 3-aminocrotonate (36) in a consecutive three- and fourcomponent sequence under relatively harsh conditions with an excess of acetic acid at high temperature for $24 \mathrm{~h}$ furnishing the heterocyclic 3-ethoxycarbonyl 2-methylpyridines 37.

Another multicomponent approach to tri- and tetrasubstituted pyridines via ethyl acetoacetate and ammonium acetate as third and fourth components furnishes pyridines in moderate yields, while yields per bond-forming step account for up to $83 \%$ and for the formation of four new bonds.

Bakulina and coauthors presented a one-pot-sequence starting with the catalytic ynone generation and subsequent transformation to pyridinium salts. Therefore, 1,8diazabicyclo[5.4.0]undec-7-ene (DBU) (38) and aluminium chloride were added to the formed alkynones furnishing tricyclic 2-aminopyridinium salts 39. The isolation of 15 examples in 10-96\% yield was possible with a broad variation of substituents for the acid chloride as well as for the alkyne components (Scheme 19). In addition, the obtained structures were corroborated by X-ray structure analyses [78]. 


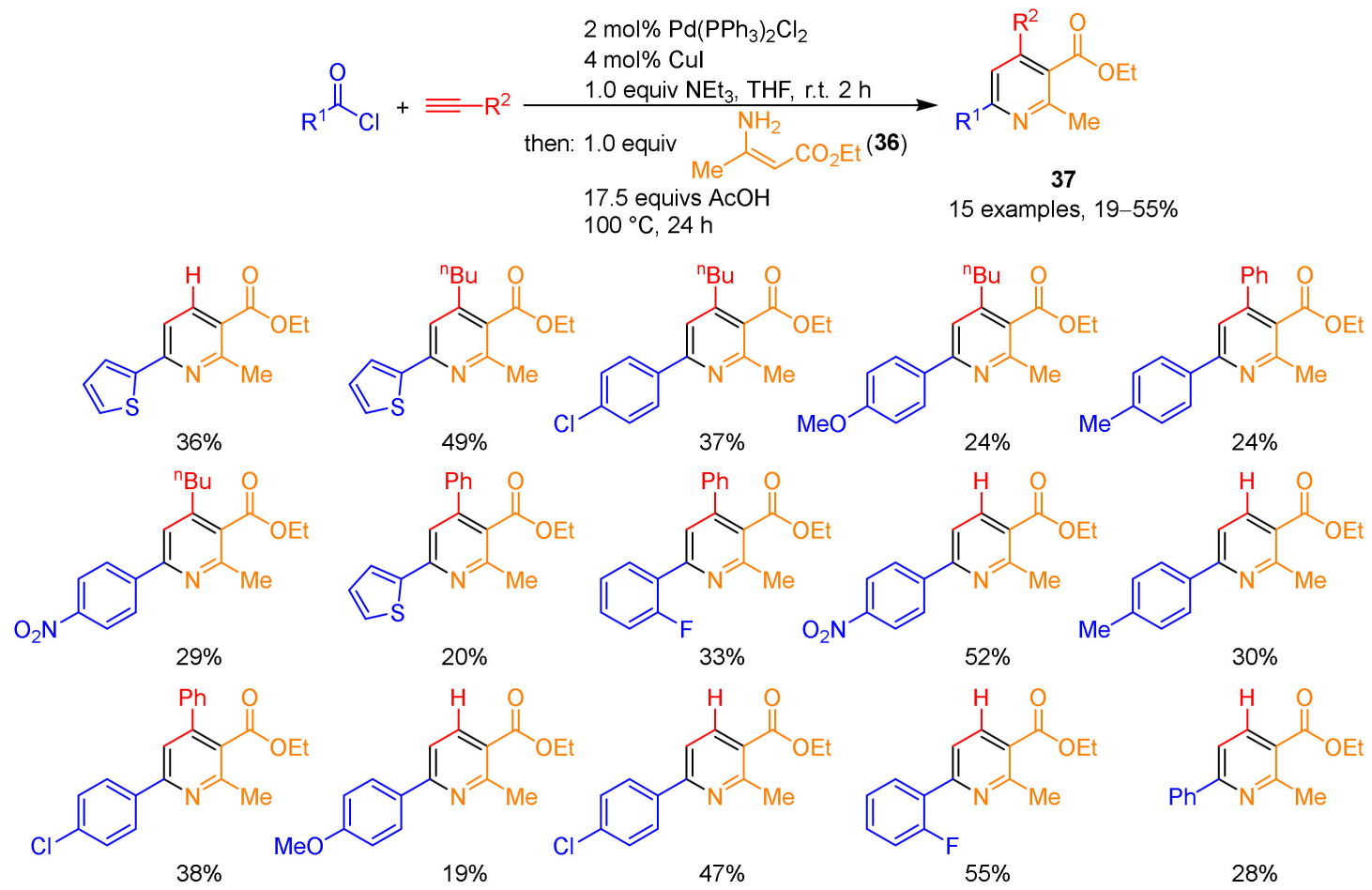

Scheme 18. Consecutive coupling-cyclocondensation formation of tri- and tetrasubstituted pyridines 37.

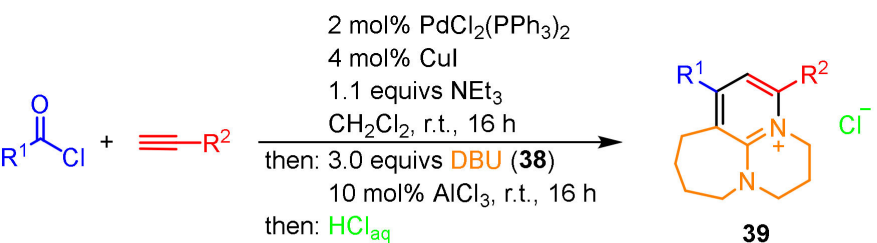

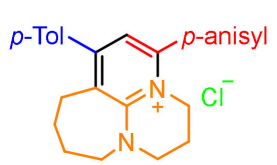

$87 \%$

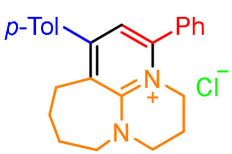

$80 \%$

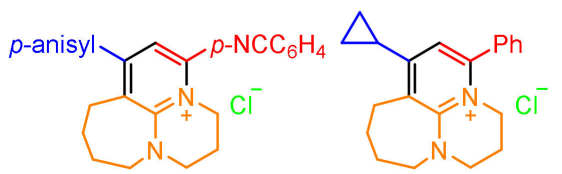

$60 \%$

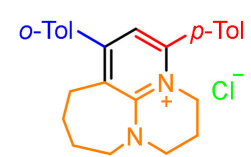

$61 \%$

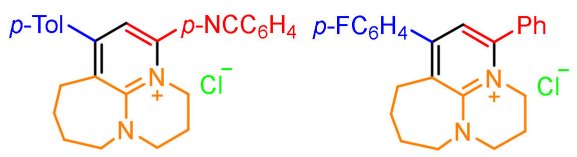

$70 \%$

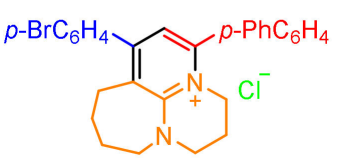

$70 \%$

$74 \%$

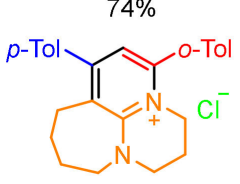

$75 \%$

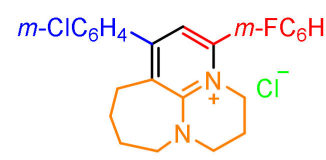

$50 \%$

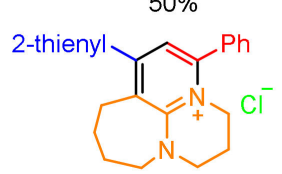

$87 \%$

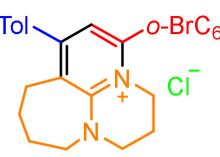

$88 \%$

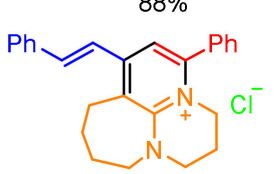

$52 \%$

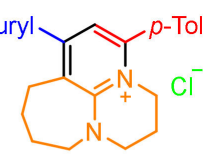

$87 \%$

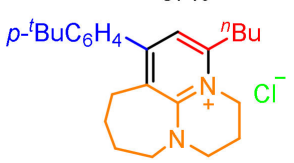

$10 \%$

Scheme 19. Consecutive MCR synthesis of tricyclic 2-aminopyridinium salts 39.

Apart from DBU, different other bicyclic amidines, such as hexahydro- $2 \mathrm{H}$-pyrido[1,2a]pyrimidine, 1,5-diazabicyclo[4.3.0]non-5-ene (DBN), as well as tetrahydro-3H-pyrrolo[1,2a]imidazole, were employed in the sequence. All but one example $\left(\mathrm{R}^{1}=p-\mathrm{BrC}_{6} \mathrm{H}_{4}\right.$, $\mathrm{R}^{2}$ = biphenyl) of the tricyclic 2-aminopyridinium salts are potent luminophores and appliable under physiological conditions. Additionally, in solution all the products' luminesce 
was intensely blue to turquoise. They are hygroscopic and highly soluble in both water and organic solvents.

\subsection{Pyrimidines}

Among the three diazines pyrimidines are particularly prominent with respect to application [79]. A quite unusual substrate for a multicomponent reaction was chosen by Cheremnykh and coauthors (Scheme 20). With 5'-ethynyllappaconitine (40) as a terminal alkyne the alkynone formation and subsequent cyclocondensation with acetamidine hydrochloride or guanidine carbonate furnished diterpene alkaloid-pyrimidine hybrid structures 41. Two examples were synthesized in good yield under consecutive one-pot conditions in a two-step fashion. Therefore, it was necessary to evaporate the solvent under reduced pressure and to replace it by acetonitrile for the terminal step [80]. According to a two-step protocol and the isolation of the ynone intermediate and severed cyclization enabled the synthesis of seven additional examples.

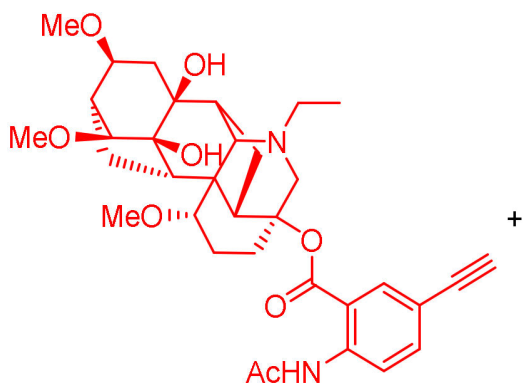

40

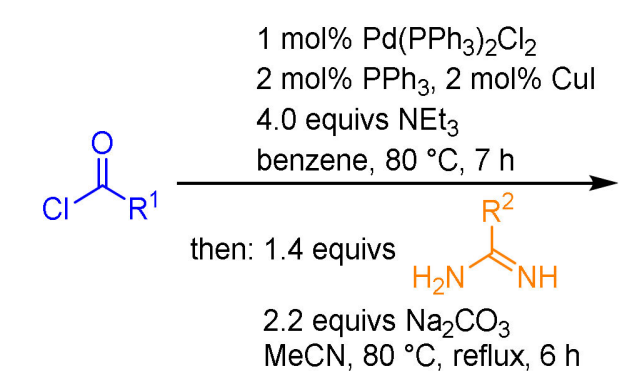

$\mathrm{MeCN}, 80^{\circ} \mathrm{C}$, reflux, $6 \mathrm{~h}$

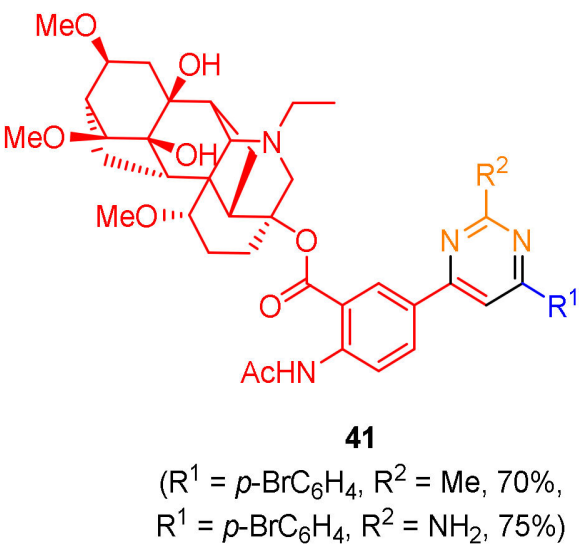

Scheme 20. Diterpene alkaloid functionalized pyrimidines 41 by a two-step couplingcyclocondensation synthesis.

\subsection{Isoquinolines}

As fused carbocyclic pyridine derivatives, isoquinolines receive an ongoing interest [74]. The Ugi four-component reaction (Ugi-4CR) was first reported in 1959 and is, to date, one of the most prominent domino multicomponent reactions inciting numerous fields of research [81]. Inspired by the Ugi-4CR, the groups of Riva and Müller disclosed a one-pot synthesis of 3-hydroxyisoquinolines focusing on a diversity-oriented approach with four different starting molecules. Eight examples of the highly functionalized isoquinolinones 42 were obtained in $45-97 \%$ yields (Scheme 21). A subsequent aromatization to 3-hydroxyisoquinoline $\mathbf{4 3}$ was also demonstrated in a one-step process; however, the yields for the final step was largely affected by the nature of starting materials, even under the same optimized conditions. The authors concluded that the conditions of the aromatization need dedicated fine-tuning, while the other three steps (Ugi/Heck/DMB removal) proceeded well for all substituents, often leading to a two-step protocol [82]. The eight isoquinolinole examples $\mathbf{4 3}$ showed intensively blue luminescence upon excitation and could be isolated in moderate-to-good yields.

Inspired by this sequence, starting as well with an Ugi-4CR of aryl aldehyde, propiolic acid, isonitrile, and 2,4-dimethoxybenzylamine furoisoquinolines 44 were synthesized in mostly good yields (Scheme 22). The conceived five-component process led to 15 examples in a rather unusual formation via a subsequent insertion-alkynylation reaction, debenzylation, and base-catalyzed terminating 5-exo-dig cycloisomerization [83]. 

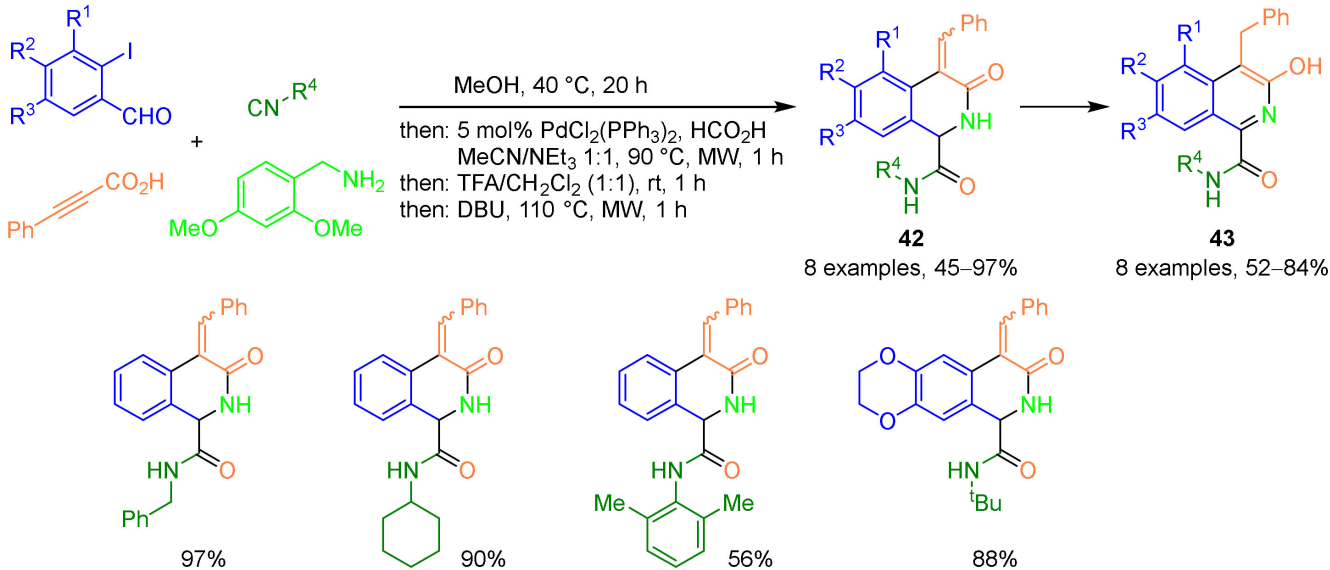

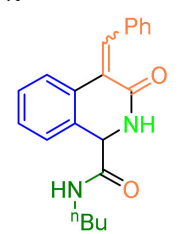

$79 \%$

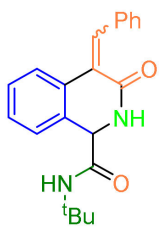

$92 \%$

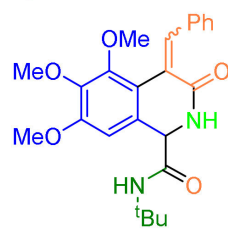

$45 \%$

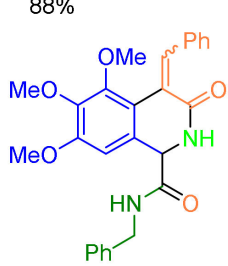

$63 \%$

Scheme 21. Two-step synthesis of 3-hydroxyisoquinolines 43 by sequential Ugi four-component reaction/reductive Heck cyclization.
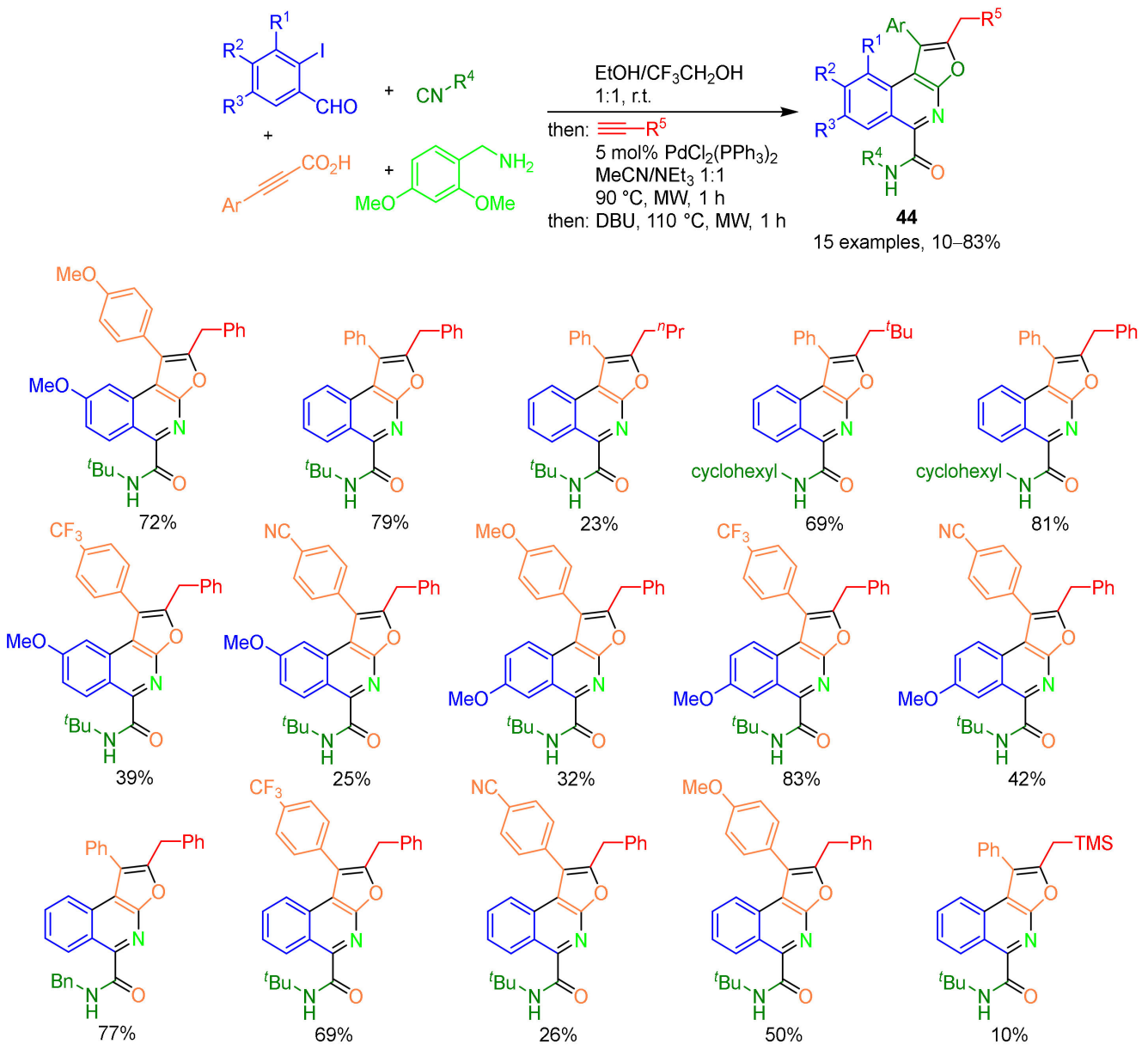

Scheme 22. Furoisoquinolines 44 by consecutive five-component Ugi-insertion-alkynylationdeprotection-cycloisomerization sequence. 


\subsection{Quinoxalines}

Quinoxalines are benzofused derivatives of pyrazines with a considerable application potential [84]. Two complementary synthetic protocols to obtain 3-ethynylquinoxaline derivatives starting from either electron-rich heteroarenes or glyoxylic acid arenes were described by Gers and coauthors [85]. These diversity-oriented approaches both proceed via en route formed glyoxylic acid chlorides and are followed by $\mathrm{Cu}$-catalyzed alkynylation. The thus formed ynediones react in a one-pot-fashion by concluding Hinsberg cyclization with 1,2-diaminoarenes and the triple bond is even addressable by a terminating fourth or fifth step in a one-pot sequence. Ten examples of 3-(2-aminovinyl)quinoxalines 45 could be isolated after concluding the Michael reaction of secondary amines in moderate-to-good yields (Scheme 23) [86].

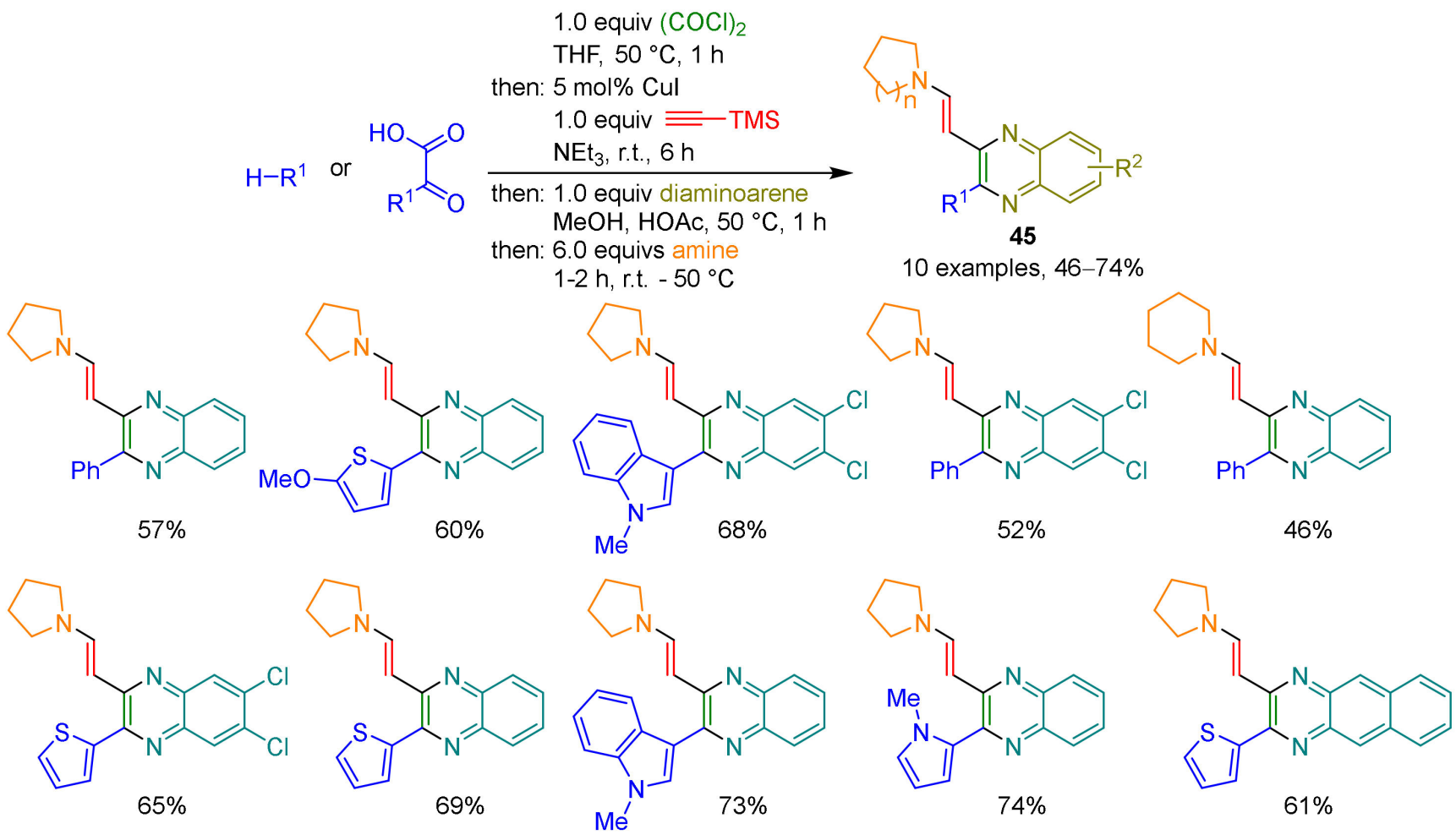

Scheme 23. Two complementary synthetic one-pot syntheses of 3-(2-aminovinyl)quinoxalines 45.

The photophysical properties of the synthesized quinoxalines show solvatochromicity as well as protochromicity and underline the charge transfer character of absorption and emission bands of the title compounds. In addition, fluorescence quenching is induced by hydrogen bonding and protonation.

A quite similar approach takes advantage of the direct activation of glyoxylic acids following the more general consecutive activation-alkynylation-cyclocondensation synthesis of 3-ethynylquinoxalines 46. The three-component synthesis furnished 24 chromophore examples in moderate to excellent yields (Scheme 24). Due to a broad substrate scope, emission solvatochromicity in a range from blue-green to deep-orange are found [87].

Starting with 2-(5-bromothiophen-2-yl)-2-oxoacetic acid (47) 5-bromothienyl 3-ethynylquinoxalines derivatives 48 are accessible in good-to-excellent yields in the sense of a three-component process (Scheme 25). While the introduced 1,2-diaminoarene moiety allows diversification of obtained products, a level 2 functionalization to extended $\pi$ systems 49, 50, and 51 is facilitated by both Buchwald-Hartwig and Suzuki coupling via the 5-bromothienyl building block 48 [88]. 


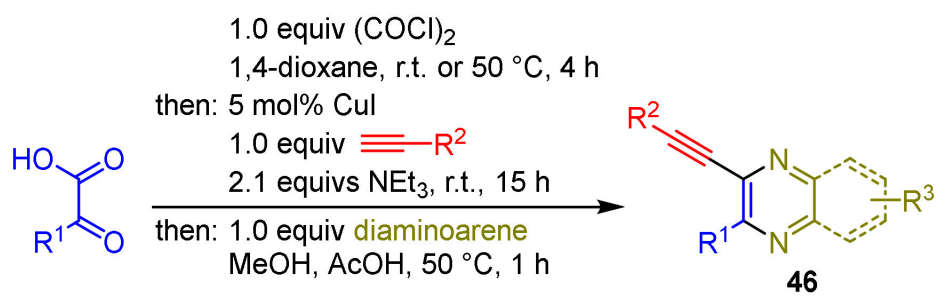<smiles>CC(C)SC#Cc1nc2ccccc2nc1-c1ccc(Br)s1</smiles>

$91 \%$<smiles>CSC#Cc1nc2ccccc2nc1-c1cccs1</smiles>

$88 \%$<smiles>CSC#Cc1nc2ccccc2nc1-c1ccc(Br)s1</smiles>

$78 \%$<smiles>CC#Cc1nc2ccccc2nc1-c1ccc(C)cc1</smiles><smiles>CSC#Cc1nc2ccccc2nc1-c1ccc(C(C)(C)C)cc1</smiles><smiles>CSC#Cc1nc2ccccc2nc1-c1ccc(N(C)C)cc1</smiles><smiles>CC#Cc1nc2cc3ccccc3cc2nc1-c1ccc(N(C)C)cc1</smiles>

$46 \%$ TIPS<smiles>CSC#Cc1nc2ccccc2nc1-c1csc2ccccc12</smiles>
TMS $86 \%$<smiles>CSC#Cc1nc(C#N)c(C#N)nc1-c1ccc(N(C)C)cc1</smiles><smiles>CC#Cc1nc2cc3ccccc3cc2nc1-c1cccs1</smiles><smiles>C#Cc1nc2ccccc2nc1-c1ccccc1</smiles>

$85 \%$<smiles>CC(C)(C)SC#Cc1nc2cc(Cl)c(Cl)cc2nc1-c1ccc(S(C)(=O)=O)cc1</smiles>
$74 \%$<smiles>CC#Cc1nc2cc(C#N)c(C)cc2nc1-c1ccc(N(C)C)cc1</smiles>

$30 \%$<smiles>[Mg][Mg]</smiles><smiles>CSC#Cc1nc2cc(Cl)c(Cl)cc2nc1-c1ccc2c(c1)c1ccccc1n2-c1ccccc1</smiles><smiles>CNc1ccc(-c2nc3ccccc3nc2C#Cc2ccccc2)cc1</smiles><smiles>COc1ccc(C#Cc2nc3ccccc3nc2-c2ccc(N(C)C)cc2)cc1</smiles><smiles>CN(C)/C=C/c1ccc(I)cc1</smiles><smiles>CC#Cc1nc2ccccc2nc1-c1ccccc1</smiles>

Scheme 24. Three-component activation-alkynylation-cyclocondensation synthesis of 3-ethynylquinoxalines 46.

An expansion of the established one-pot syntheses of quinoxalines can be carried out with a concluding $\mathrm{Cu}$-catalyzed alkyne-azide cycloaddition (CuAAC) for transforming the in situ formed triple bond into conjugated heterocycles. Desilylation is readily received upon addition of potassium fluoride in the presence of azides, thus, resulting in 18 examples of 3-triazolylquinoxalines $\mathbf{5 2}$ in moderate-to-excellent yields (Scheme 26). Not only the diversity rich synthesis protocol, but also average yields per bond-forming step of $90 \%$ clearly support the superiority of the one-pot concept over stepwise reaction protocols [89]. 


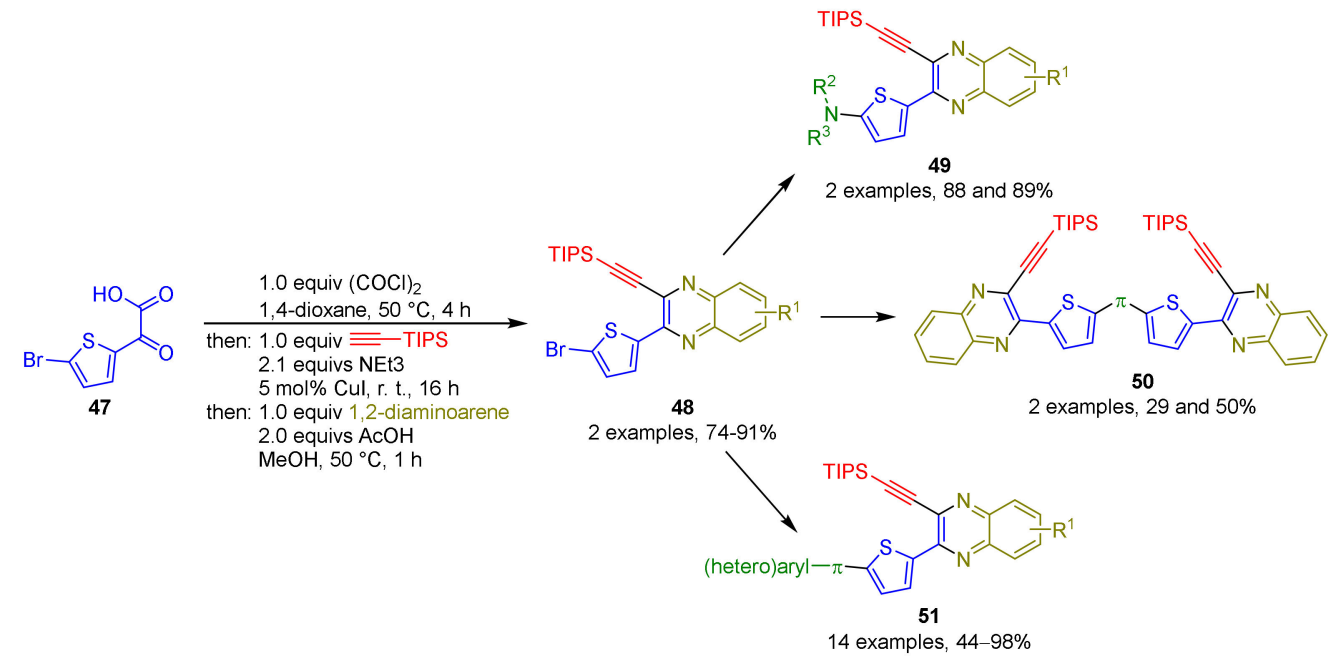

Scheme 25. Consecutive three-component access to 5-bromothienyl 3-ethynylquinoxalines and level 2 transformation to $\pi$-conjugation expanded 5-(hetero)aryl-thien-2-yl substituted 3-ethynyl quinoxalines 49,50 , and 51 .
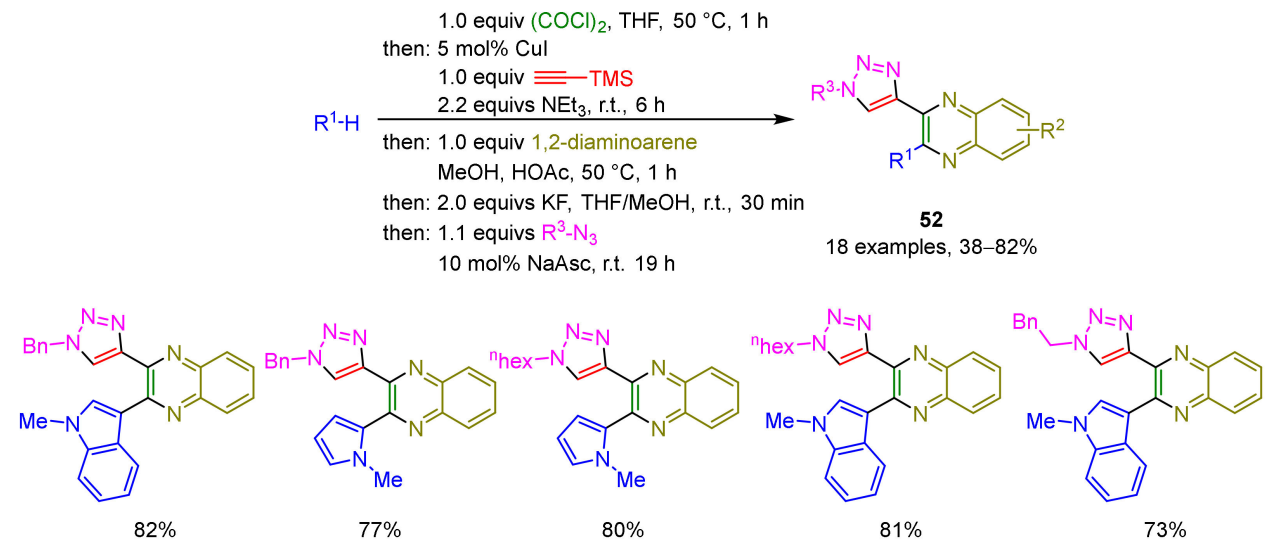<smiles></smiles>

$38 \%$

$53 \%$

$74 \%$

$74 \%$<smiles></smiles>

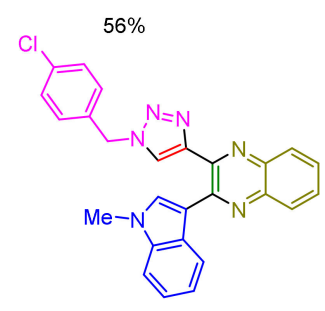

$48 \%$
$69 \%$

$72 \%$

$42 \%$

$56 \%$

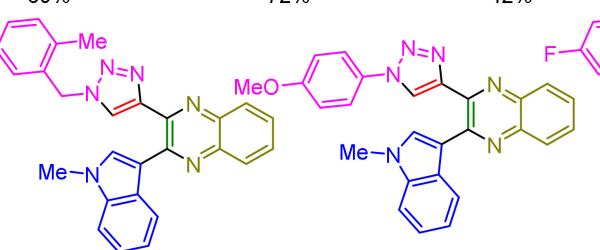

$46 \%$

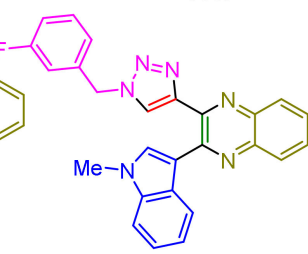

$58 \%$

Scheme 26. Consecutive five-component glyoxylation-alkynylation-cyclocondensation-CuAAC synthesis of 3-triazolylquinoxalines 52 . 


\section{Oxygen Containing Heterocycles by Multicomponent Syntheses}

This chapter summarizes recent multicomponent syntheses of isoxazoles, pyranones, coumarins, and oxazaborinines based upon the catalytic entry to alkynoyl intermediates.

\subsection{Isoxazoles}

Isoxazoles are constitutional isomers of oxazoles with broad application [90]. Görgen and coworkers described a facile synthesis isoxazoles under copper-free palladium catalysis. Isoxazoles were formed in a consecutive three-component sequence of alkynylation of aroyl chloride and alkyne followed by cyclization withsodium azide and acetic acid at room temperature. The procedure waives high catalyst loading for the alkynylation step as well as high temperature for the utilization of an azide. In addition, remarkably, the oxygen of the aroyl chloride is embedded in the final product. The authors assume $\mathrm{Cu}(\mathrm{I}) \mathrm{N}_{3}$ complex formation from $\mathrm{Cu}(\mathrm{I})$ and azide anions. After the loss of nitrogen copper nitride is generated that might transform alkynones to enaminones. Therefore, copper-free conditions for the alkynylation have to be considered, and finally, nine examples of 3,5-di(hetero)arylsubstituted isoxazoles 53 are obtained in poor-to-good yields (Scheme 27) [91].<smiles>Fc1ccccc1-c1cc(-c2ccccc2Cl)on1</smiles>

$51 \%$

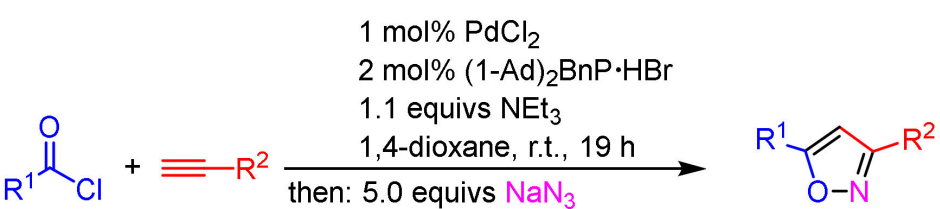
5.0 equivs $\mathrm{AcOH}$ r.t., $4 \mathrm{~h}$<smiles>Clc1ccccc1-c1cc(-c2ccccc2)no1</smiles>
$72 \%$
9 examples, $10-72 \%$<smiles>c1ccc(-c2cc(-c3cccs3)on2)cc1</smiles>

$32 \%$<smiles>c1ccc(-c2cc(-c3cccnc3)on2)cc1</smiles>

$51 \%$<smiles>COc1ccc(-c2cc(CC(C)C)no2)cc1</smiles>

$10 \%$<smiles>COC(=O)c1ccc(-c2cc(-c3ccc(OC)cc3)on2)cc1</smiles>

$29 \%$<smiles>COc1ccc(-c2cc(-c3ccccc3)no2)cc1</smiles>

$71 \%$<smiles>O=C(O)Cc1cc(-c2ccccc2Cl)on1</smiles>

$12 \%$

Scheme 27. Disubstituted isoxazoles 53 by consecutive three-component alkynylationcyclocondensation sequence.

Another alluring approach to isoxazoles was described by Thirukovela and coworkers employing hydroxylammonium chloride and sodium acetate in a regioselective one-pot synthesis. Therefore, in a Cu-free alkynylation of aroyl chlorides and aryl acetylenes alkynone moieties are generated in aqueous PEG-400 solution in the presence of Pdnanoparticles (PdNPs). Depending on the reaction conditions a beneficial effect of the homogeneously dispersed PdNPs is their recycling after the reaction. Without losing significant catalytic efficiency the PdNPs were reused in five successive cycles. In this process, 14 examples of isoxazoles $\mathbf{5 4}$ were obtained in good-to-excellent yields (Scheme 28) [92]. In addition, 19 examples of 1,3,5-substituted pyrazoles were obtained in 75-92\% yield by adding (phenyl)hydrazine to the in situ generated ynones underlining the versatility of the one-pot sequence. Similarly, Deden and coauthors showed that this cyclocondensation route was readily elaborated to a sequentially Pd-catalyzed four-component synthesis of intensively fluorescent biaryl-substituted isoxazoles with donor-acceptor decoration in moderate-to-good yields [93]. 


\subsection{Pyranones}

Pyranone derivatives find broad application in various fields [94]. Commencing with the in situ generation of alkynones from (hetero)aroyl chlorides and terminal alkynes, Breuer and coauthors described a promising one-pot access $\alpha$-pyrones 55. Therefore, only low catalyst loading $\mathrm{PdCl}_{2}\left(\mathrm{PPh}_{3}\right)_{2}(0.25 \mathrm{~mol} \%)$ and $\mathrm{CuI}(0.50 \mathrm{~mol} \%)$ is needed to give reactive intermediates for the reaction with malonates furnishing unsaturated lactones 55 bearing electron-donating and electron-withdrawing aryl substituents as well as heterocyclic groups. From this three-component reaction arose 14 pyranones in moderate-to-good yields (Scheme 29) [95].
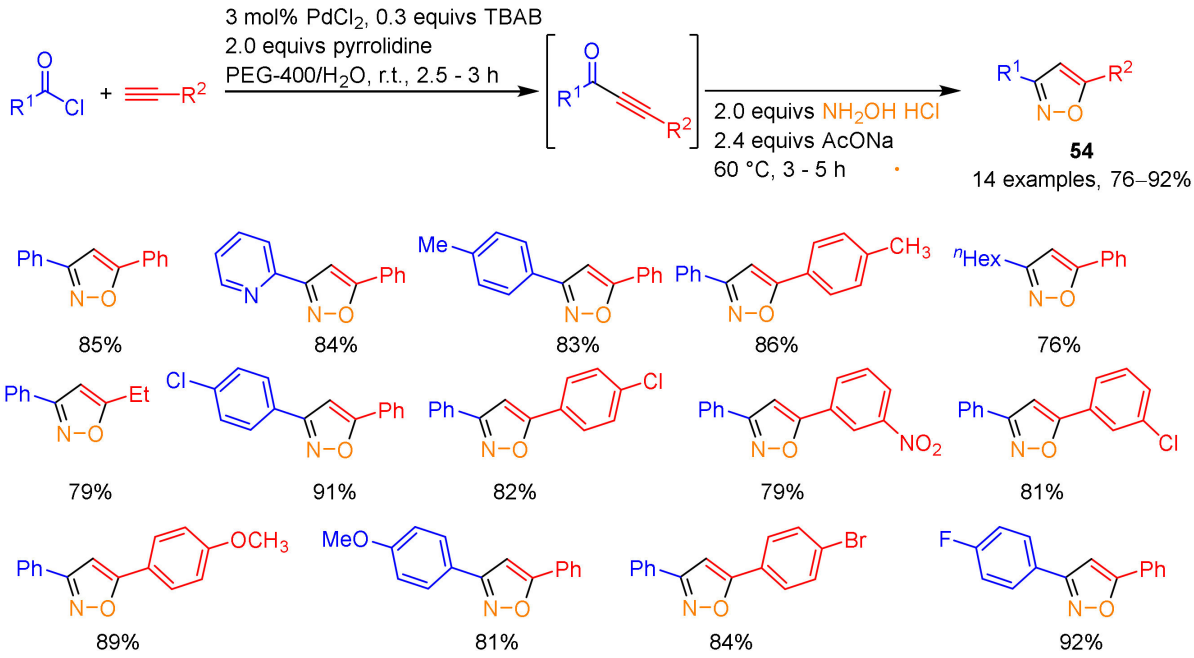

Scheme 28. Isoxazole synthesis 54 by consecutive three-component alkynylation-cyclocondensation sequence.
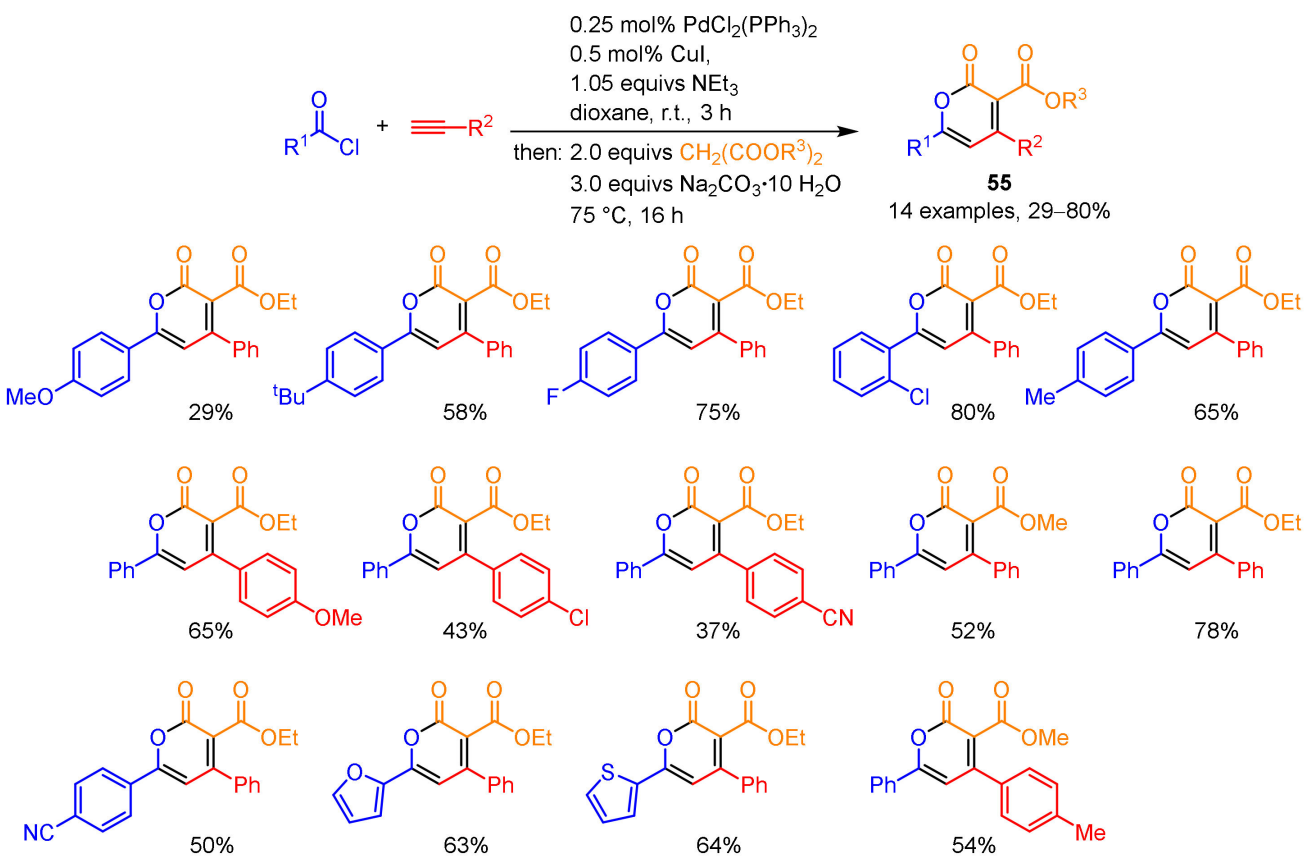<smiles>CCOc1cccc(-c2ccco2)c1C(=O)O</smiles><smiles>CCOC(=O)c1c(O)oc(-c2cccs2)c1C(=O)O</smiles><smiles>COC(=O)c1c(-c2ccccc2)cc([N+](=O)[O-])oc1=O</smiles>

Scheme 29. $\alpha$-Pyridones 55 by consecutive three-component coupling-cyclocondensation sequence.

Moreover, a consecutive four-component alkynylation-Michael addition-cyclocondensation-ammonolysis sequence has been conceived by adding an excess of ammonia in the final step. After reaction at $90^{\circ} \mathrm{C}$ for $4 \mathrm{~h}$ a mixture of $\alpha$-pyridones with and without ester 
functionality were obtained in moderate yields, while the ester separated $\alpha$-pyridones were in the majority because of the concomitant acyl cleavage [96].

\subsection{Coumarins}

Coumarins constitute natural products and cover a broad spectrum of biological properties [94]. Papadopoulos and coauthors described a consecutive three-component coupling-addition sequence of diverse substituted coumarin derivatives. Starting from triflyl coumarins, terminal alkynes and amino components the synthesis takes advantage of the vinyloguous Michael system for an addition of the secondary amines. Upon applying a strictly equimolar ratio of all three reactants and the auxiliary base, 23 examples of E-configured merocyanines 56 in moderate-to-excellent yields are obtained (Scheme 30). The substrate scope ranges from neutral to electron-rich coumarins, alkyl, silyl and aryl acetylenes as well as acyclic and ali(hetero)cyclic secondary amines [97].

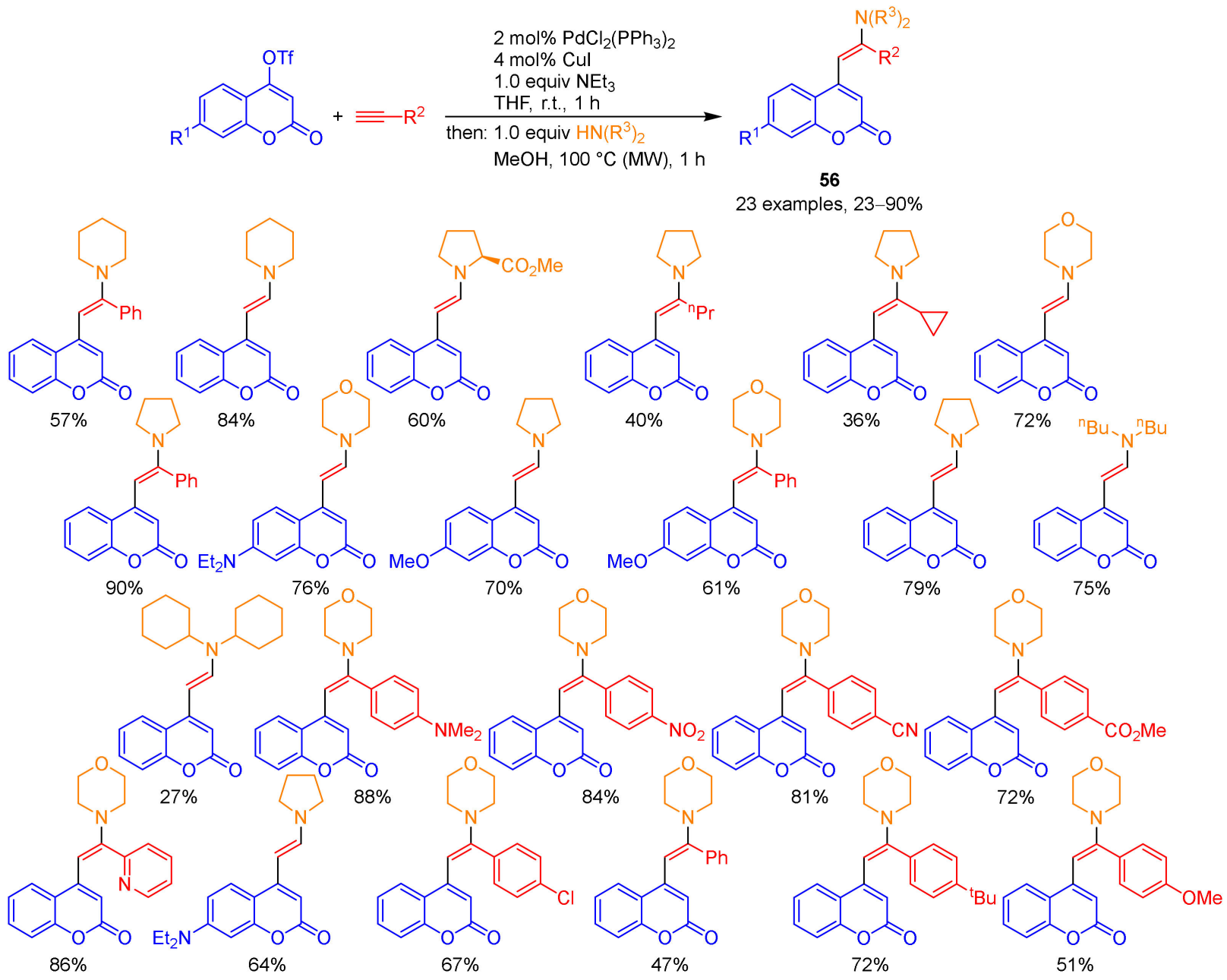

Scheme 30. Coumarin-based merocyanines 56 by consecutive three-component alkynylationaddition sequence.

\subsection{Oxazaborinines}

Difluoro oxazaborinines are highly polar $\pi$-systems with interesting electronic ground and excited state properties [98]. (Hetero)aroyl chlorides, alkynes, anilines, and boron trifluoride react according to Dohe and coauthors a consecutive four-component one-pot sequence to give difluoro oxazaborinines. Therefore, catalytically generated alkynones are directly transformed with added amines and boron trifluoride as the activating Lewis acid to furnish 29 examples of difluoro oxazaborinines $\mathbf{5 7}$ in poor-to-excellent yields (Scheme 31). While electron-rich amines hampered a domino process, a stepwise addition of the amine 
to the formed alkynone and subsequent boron trifluoride circumvented this issue. The obtained oxazaborinines show solid state emission upon UV excitation, whereas no example displayed emission in solution [99].

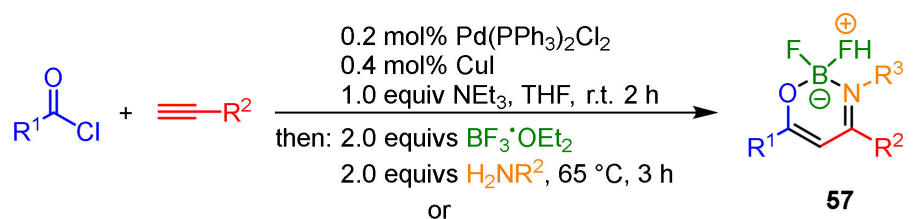

then: 2.0 equivs $\mathrm{H}_{2} \mathrm{NR}^{2}, 65^{\circ} \mathrm{C}, 3 \mathrm{~h}$

29 examples, $5-84 \%$

then: 2.0 equivs $\mathrm{BF}_{3} \cdot \mathrm{OEt}_{2}, 65^{\circ} \mathrm{C}, 3 \mathrm{~h}$
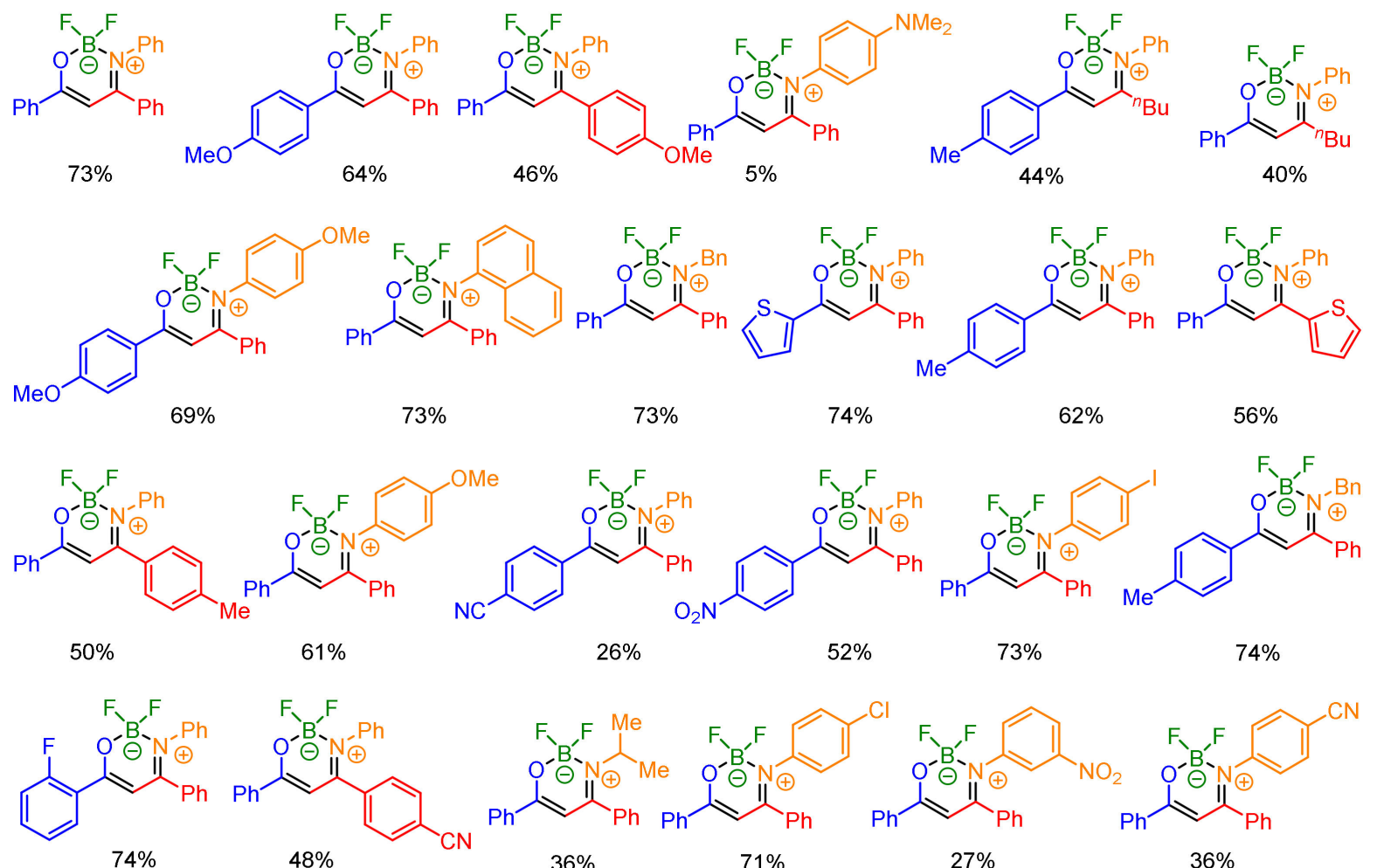

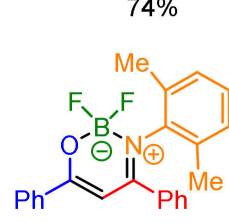

$51 \%$

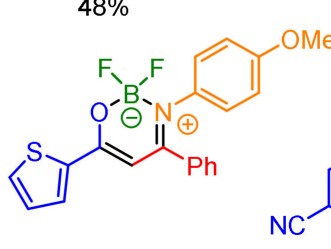

$47 \%$

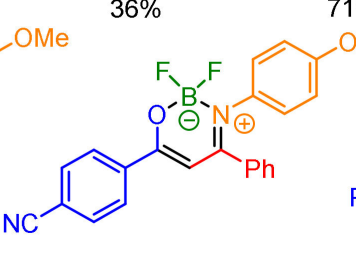

$46 \%$<smiles>COc1ccc(C2=CC(c3ccccc3)=[N+](F)[B-]2(F)F)cc1</smiles>

$84 \%$

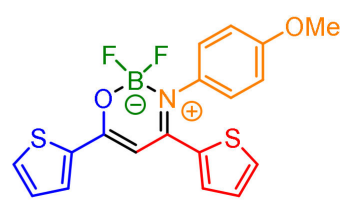

$66 \%$

Scheme 31. Difluoro oxazaborinines 57 by consecutive four-component coupling-additionborylation sequence.

\section{Thiophenes by Multicomponent Syntheses}

Apart from oxygen and nitrogen, sulfur is a valuable heteroatom in the composition of heterocycles. Five membered thiophenes are decisive building blocks not only for natural products and pharmaceutical active compounds [100], but also for materials in electronic and opto-electronic devices [101]. The rising demand for efficient synthetic strategies of sulfur containing heterocycles has been reviewed mainly focused on ring-forming multicomponent reactions [102]. Teiber and coauthors described a one-pot protocol of diethyl terthiophene-5,5"-dicarboxylates starting with 2,5-bis(trimethylsilyl-ethynyl) thiophene [103]. This compound is a stable storage analogue of the sensitive 2,5-diethynyl thiophene. After in situ desilylation and extractive workup subsequent Sonogashira coupling with acid chlorides terminated by a Fiesselmann reaction with ethyl 2-mercaptoacetate 
furnishes the title compounds. In the sense of a pseudo five-component syntheses these terthiophene diesters 58 were obtained in moderate-to good-yields (Scheme 32).

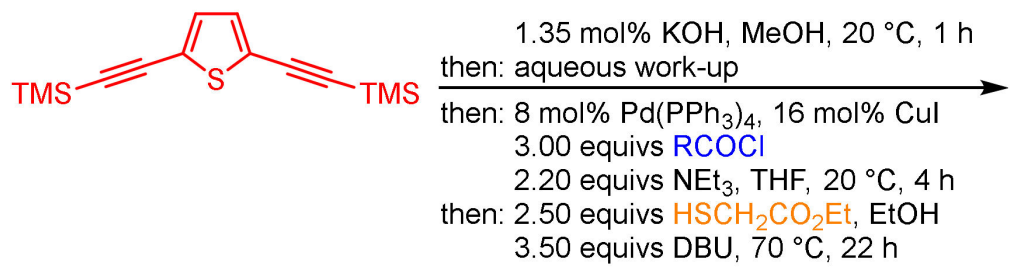

(15\%)

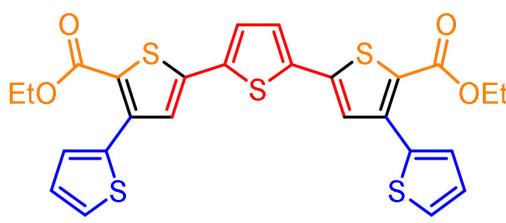

$67 \%$<smiles>[R]c1cc(-c2ccc(-c3cc([R])c(C(=O)OCC)s3)s2)sc1C(=O)OCC</smiles>

58

3 examples, 33-75\%

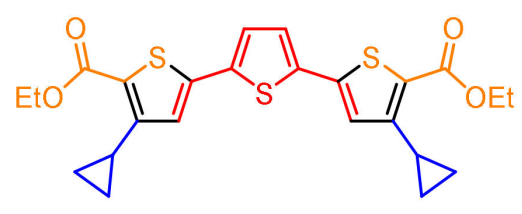

$33 \%$

Scheme 32. Diethyl terthiophene- $5,5^{\prime \prime}$-dicarboxylates 58 by consecutive pseudo five-component coupling-cyclocondensation sequence.

The diethyl dicarboxylates 58 acted as intermediates, which were transformed in a second step into 11 examples of corresponding 5,5' -diamide substituted terthiophenes in good-to-excellent yields [104]. Apart from the two-step protocol a chosen example was reacted in an extended pseudo-seven component reaction in a one-pot fashion. Therefore, the reaction conditions of the terminating amidation step had to be adjusted by increasing the catalyst loading, added amine and reaction time leading to an overall yield of $54 \%$ of the illustrated example. The 5,5"-diacceptor substituted terthiophene products luminesce intensively blue in solution and they possess reversible oxidation potentials between 300 and $1550 \mathrm{mV}$. Therefore, the dyes can be considered as redox-switchable systems.

\section{Conclusions and Outlook}

As outlined in this review, MCRs via transition metal catalyzed generation of alkynoyl intermediates display a variegated entry to myriads of diversity-oriented syntheses of heterocycles. Moreover, the alkynone are formed under mild reaction conditions and their generation is compatible with a plethora of polar functionalities. Consequently, novel consecutive multicomponent entries to chromophores are thereby enabled. Methodologically, one-pot processes are clearly advantageous over classical approaches, especially upon underlining the perfect compatibility of consecutive one-pot protocols in the sense of programmed reactivity. Evidently, catalytic formation of alkynoyl functionalities has set the stage for modular syntheses of heterocycles in numerous applications.

Author Contributions: Conceptualization, J.N. and T.J.J.M.; writing—original draft preparation, J.N.; writing-review and editing, T.J.J.M.; supervision, T.J.J.M.; project administration, T.J.J.M.; funding acquisition, T.J.J.M. All authors have read and agreed to the published version of the manuscript.

Funding: This research was funded by Fonds der Chemischen Industrie, ad personam funding for T.J.J.M.

Acknowledgments: The work reported in this review predominantly originates from our research group. Therefore, we are particularly grateful for the dedication and the intellectual input by the individuals, who are mentioned as the first authors of the corresponding publications. In addition, we also thank all coauthors of these publications.

Conflicts of Interest: The authors declare no conflict of interest. 


\section{References}

1. Zhu, J.; Bienaymé, H. Multicomponent Reactions; Wiley-VCH Verlag GmbH \& Co. KGaA: Weinheim, Germany, 2006.

2. Zhu, J.; Wang, Q.; Wang, M. (Eds.) Multicomponent Reactions in Organic Synthesis; Wiley-VCH Verlag GmbH \& Co. KGaA: Weinheim, Germany, 2014.

3. Müller, T.J.J. Relative Reactivities of Functional Groups as the Key to Multicomponent Reactions. In Multicomponent Reactions 1. General Discussion and Reactions Involving a Carbonyl Compound as Electrophilic Component; Müller, T.J.J., Ed.; Science of Synthesis Series; Georg Thieme Verlag KG: Stuttgart, Germany, 2014; pp. 5-27.

4. Deilhof, K.; Müller, T.J.J. Alkynes in Multicomponent Synthesis of Heterocycles. In Multicomponent Reactions in Organic Synthesis; Zhu, J., Wang, Q., Wang, M., Eds.; Wiley-VCH Verlag GmbH \& Co. KGaA: Weinheim, Germany, 2014; pp. $333-378$.

5. Müller, T.J.J. Synthesis of Heterocycles by Pd-catalyzed and Pd-catalysis Initiated Multi-Component Reactions. In Applied Homogeneous Catalysis with Organometallic Compounds; Beller, M., Ed.; Wiley-VCH Verlag GmbH \& Co. KGaA: Weinheim, Germany, 2018; pp. 1463-1483.

6. Algieri, V.; Algieri, C.; Maiuolo, L.; de Nino, A.; Pagliarani, A.; Tallarida, M.A.; Trombetti, F.; Nesci, S. 1,5-Disubstituted-1,2,3triazoles as inhibitors of the mitochondrial $\mathrm{Ca}^{2+}$-activated $\mathrm{F}_{1} \mathrm{~F}_{\mathrm{O}}-\mathrm{ATP}($ hydrol)ase and the permeability transition pore. Ann. N. $Y$. Acad. Sci. 2021, 1485, 43-85. [CrossRef] [PubMed]

7. Maiuolo, L.; Algieri, V.; Russo, B.; Tallarida, M.A.; Nardi, M.; di Gioia, M.L.; Merchant, Z.; Merino, P.; Delso, I.; de Nino, A. Synthesis, Biological and In Silico Evaluation of Pure Nucleobase-Containing Spiro (Indane-Isoxazolidine) Derivatives as Potential Inhibitors of MDM2-p53 Interaction. Molecules 2019, 24, 2909. [CrossRef] [PubMed]

8. Maiuolo, L.; Feriotto, G.; Algieri, V.; Nardi, M.; Russo, B.; di Gioia, M.L.; Furia, E.; Tallarida, M.A.; Mischiati, C.; de Nino, A. Antiproliferative Activity of Novel Isatinyl/Indanyl Nitrones (INs) as Potential Spin Trapping of Free Radical Intermediates. MedChemComm 2018, 9, 299-304. [CrossRef] [PubMed]

9. Müllen, K.; Wegner, G. (Eds.) Electronic Materials: The Oligomer Approach; Wiley-VCH Verlag GmbH \& Co. KGaA: Weinheim, Germany, 2008.

10. Shirota, Y.; Kageyama, H. Charge Carrier Transporting Molecular Materials and Their Applications in Devices. Chem. Rev. 2007, 107, 953-1010. [CrossRef] [PubMed]

11. Walzer, K.; Maennig, B.; Pfeiffer, M.; Leo, K. Highly Efficient Organic Devices Based on Electrically Doped Transport Layers. Chem. Rev. 2007, 107, 1233-1271. [CrossRef] [PubMed]

12. Coropceanu, V.; Cornil, J.; da Silva Filho, D.A.; Olivier, Y.; Silbey, R.; Brédas, J.-L. Charge Transport in Organic Semiconductors. Chem. Rev. 2007, 107, 926-952. [CrossRef]

13. Torsi, L.; Magliulo, M.; Manoli, K.; Palazzo, G. Organic field-effect transistor sensors: A tutorial review. Chem. Soc. Rev. 2013, 42, 8612-8628. [CrossRef]

14. Müllen, K.; Scherf, U. (Eds.) Organic Light Emitting Devices: Synthesis, Properties and Applications; Wiley-VCH Verlag GmbH \& Co. KGaA: Weinheim, Germany, 2006.

15. Sun, S.-S.; Dalton, L.R. Introduction to Organic Electronic and Optoelectronic Materials and Devices, 2nd ed.; CRC Press: New York, NY, USA, 2016.

16. Mishra, A.; Fischer, M.K.; Bäuerle, P. Metal-Free Organic Dyes for Dye-Sensitized Solar Cells: From Structure: Property Relationships to Design Rules. Angew. Chem. Int. Ed. 2009, 48, 2474-2499. [CrossRef]

17. Levi, L.; Müller, T.J.J. Multicomponent syntheses of functional chromophores. Chem. Soc. Rev. 2016, 45, 2825-2846. [CrossRef]

18. Levi, L.; Müller, T.J.J. Multicomponent Syntheses of Fluorophores Initiated by Metal Catalysis. Eur. J. Org. Chem. 2016, 2016, 2907-2918. [CrossRef]

19. Müller, T.J.J. Multi-component Synthesis of Fluorophores via Catalytic Generation of Alkynoyl Intermediates. Drug Discov. Today Technol. 2018, 29, 19-26. [CrossRef]

20. D'Souza, D.M.; Müller, T.J.J. Multi-Component Syntheses of Heterocycles by Transition Metal Catalysis. Chem. Soc. Rev. 2007, 36, 1095-1108. [CrossRef]

21. Müller, T.J.J. Palladium-Copper Catalyzed Alkyne Activation as an Entry to Multi-component Syntheses of Heterocycles. Top. Heterocycl. Chem. 2010, 25, 25-94.

22. Whittaker, R.E.; Dermenci, A.; Dong, G. Synthesis of Ynones and Recent Application in Transition-Metal-Catalyzed Reactions. Synthesis 2015, 48, 161-183.

23. Nájera, C.; Sydnes, L.K.; Yus, M. Conjugated Ynones in Organic Synthesis. Chem. Rev. 2019, 119, 11110-11244. [CrossRef]

24. Gers-Panther, C.F.; Müller, T.J.J. Multicomponent Syntheses of Heterocycles Initiated by Catalytic Generation of Ynones and Ynediones. In Advances in Heterocyclic Chemistry: Heterocyclic Chemistry in the 21st Century: A Tribute to Alan Katritzky; Scriven, E.F.V., Ramsden, C.A., Eds.; Elsevier: Amsterdam, The Netherlands, 2016; Volume 120, pp. 67-98.

25. Willy, B.; Müller, T.J.J. Multi-component heterocycle syntheses via catalytic generation of alkynones. Curr. Org. Chem. 2009, 13, 1777-1790. [CrossRef]

26. Sonogashira, K.; Tohda, Y.; Hagihara, N. A convenient synthesis of acetylenes: Catalytic substitutions of acetylenic hydrogen with bromoalkenes, iodoarenes and bromopyridines. Tetrahedron Lett. 1975, 16, 4467-4470. [CrossRef]

27. Tohda, Y.; Sonogashira, K.; Hagihara, N. A Convenient Synthesis of 1-Alkynyl Ketones and 2-Alkynamides. Synthesis 1977, 1977, 777-778. [CrossRef] 
28. Chinchilla, R.; Nájera, C. The Sonogashira Reaction: A Booming Methodology in Synthetic Organic Chemistry. Chem. Rev. 2007, 107, 874-922. [CrossRef]

29. Karpov, A.S.; Müller, T.J.J. New Entry to a Three-Component Pyrimidine Synthesis by TMS-Ynones via Sonogashira Coupling Org. Lett. 2003, 5, 3451-3454. [CrossRef]

30. D'Souza, D.M.; Müller, T.J.J. Catalytic Alkynone Generation by Sonogashira Reaction and its Application in Three-component Pyrimidine Synthesis. Nat. Protoc. 2008, 3, 1660-1665. [CrossRef]

31. Nordmann, J.; Breuer, N.; Müller, T.J.J. Efficient Consecutive Four-Component Synthesis of 5-Acylpyrid-2-ones Initiated by Copper-Free Alkynylation. Eur. J. Org. Chem. 2013, 2013, 4303-4310. [CrossRef]

32. Boersch, C.; Merkul, E.; Müller, T.J.J. Catalytic Syntheses of N-Heterocyclic Ynones and Ynediones by In Situ Activation of Carboxylic Acids with Oxalyl Chloride. Angew. Chem. Int. Ed. 2011, 50, 10448-10452. [CrossRef]

33. Merkul, E.; Oeser, T.; Müller, T.J.J. Consecutive Three-Component Synthesis of Ynones by Decarbonylative Sonogashira Coupling Chem. Eur. J. 2009, 15, 5006-5011. [CrossRef]

34. Götzinger, A.C.; Müller, T.J.J. Rapid access to unsymmetrically substituted alkynes by sequentially palladium-catalyzed one-pot processes. Org. Biomol. Chem. 2016, 14, 3498-3500. [CrossRef]

35. Ahmed, M.S.M.; Mori, A. Carbonylative Sonogashira Coupling of Terminal Alkynes with Aqueous Ammonia. Org. Lett. 2003, 5, 3057-3060. [CrossRef]

36. Karpov, A.S.; Merkul, E.; Rominger, F.; Müller, T.J.J. Concise Syntheses of Meridianins via Carbonylative Alkynylation and A Novel Four-Component Pyrimidine Synthesis. Angew. Chem. Int. Ed. 2005, 44, 6951-6956. [CrossRef]

37. $\mathrm{Wu}, \mathrm{X}$.-F.; Neumann, H.; Beller, M. Palladium-catalyzed carbonylative coupling reactions between Ar-X and carbon nucleophiles. Chem. Soc. Rev. 2011, 40, 4986-5009. [CrossRef]

38. Cui, M.; Wu, H.; Jian, J.; Wang, H.; Liu, C.; Daniel, S.; Zeng, Z. Palladium-catalyzed Sonogashira coupling of amides: Access to ynones via C-N bond cleavage. Chem. Comm. 2016, 52, 12076-12079. [CrossRef]

39. Götzinger, A.C.; Michaelis, C.S.; Müller, T.J.J. 3-Phenothiazinyl propiolates-Fluorescent electrophores by Sonogashira coupling of ethyl propiolate. Dyes Pigm. 2017, 143, 308-316. [CrossRef]

40. Albano, G.; Interlandi, S.; Evangelisti, C.; Aronica, L.A. Polyvinylpyridine-Supported Palladium Nanoparticles: A Valuable Catalyst for the Synthesis of Alkynyl Ketones via Acyl Sonogashira Reactions. Catal. Lett. 2020, 150, 652-659. [CrossRef]

41. Sharma, R.K.; Yadav, M.; Gaur, R.; Gupta, R.; Adholeya, A.; Gawande, M.B. Synthesis of Iron Oxide Palladium Nanoparticles and Their Catalytic Applications for Direct Coupling of Acyl Chlorides with Alkynes. ChemPlusChem 2016, 81, 1312-1319. [CrossRef] [PubMed]

42. Loganathan, R.K.; Ramachandra, S.N.; Shekharappa; Sureshbabu, V.V. Montmorillonite K-10-Supported Palladium Nanoparticles for Copper-Free Acyl Sonogashira Reaction. ChemistrySelect 2017, 2, 8059-8062. [CrossRef]

43. Zhou, B.; Guo, S.; Fang, Z.; Yang, Z.; Guo, K. Copper-catalyzed aerobic oxidative coupling of terminal alkynes with $\alpha$-carbonyl aldehydes: An expedient approach toward ynediones. Tetrahedron Lett. 2019, 60, 150914. [CrossRef]

44. Götzinger, A.C.; Müller, T.J.J. Pyrazoles. In Science of Synthesis, Houben-Weyl; Carreira, E.M., Ed.; Science of Synthesis Knowledge Updates; Georg Thieme Verlag: Stuttgart, Germany; New York, NY, USA, 2017; Volume 3, pp. 1-128.

45. Elguero, J.; Silva, A.M.S.; Tomé, A.C. Five-Membered Heterocycles: 1, 2-Azoles. Part 1. Pyrazoles. In Modern Heterocyclic Chemistry; Alvarez-Buila, J., Vaquero, J.J., Barluenga, J., Eds.; Wiley-VCH Verlag GmbH \& Co. KGaA: Weinheim, Germany, 2011; Volume 2, pp. 635-725.

46. Marella, A.; Rahmat, A.M.; Tauquir, A.M.; Saha, R.; Tanwar, O.; Akhter, M.; Shaquiquzzaman, M.; Mumtaz, A.M. Pyrazolines: A biological review. Mini. Rev. Med. Chem. 2013, 13, 921-931. [CrossRef]

47. Görgen, C.; Boden, K.; Reiss, G.J.; Frank, W.; Müller, T.J.J. One-pot activation-alkynylation-cyclization synthesis of 1,5-diacyl-5hydroxypyrazolines in a consecutive three-component fashion. Beilstein J. Org. Chem. 2019, 15, 1360-1370. [CrossRef]

48. Götzinger, A.C.; Theßeling, F.A.; Hoppe, C.; Müller, T.J.J. Rapid One-Pot Coupling-Coupling-Cyclocondensation Synthesis of Fluorescent Pyrazoles. J. Org. Chem. 2016, 81, 10328-10338. [CrossRef]

49. Sakamoto, T.; Shiga, F.; Yasuhara, A.; Uchiyama, D.; Kondo, Y.; Yamanaka, H. Preparation of Ethyl Arylpropiolates from Aryl Iodides by Palladium-Catalyzed Cross-Coupling Reaction. Synthesis 1992, 1992, 746-748. [CrossRef]

50. Niedballa, J.; Reiss, G.J.; Müller, T.J.J. Consecutive Three-Component Coupling-Addition Synthesis of $\beta$-Amino Enoates and 3-Hydroxypyrazoles via Ethyl 3-Arylpropiolates. Eur. J. Org. Chem. 2020, 2020, 5019-5024. [CrossRef]

51. Niesobski, P.; Klukas, F.; Berens, H.; Makhloufi, G.; Janiak, C.; Müller, T.J.J. De novo Ring Forming Consecutive Four-component Syntheses of 4-Pyrazolyl-1,2,3-triazoles from TIPS-Butadiyne as a C4-Building Block. J. Org. Chem. 2018, 83, 4851-4858. [CrossRef]

52. Chen, Q.; Yao, F.; Yin, L.; Cai, M. A highly efficient heterogeneous palladium-catalyzed cascade three-component reaction of acid chlorides, terminal alkynes and hydrazines leading to pyrazoles. J. Organomet. Chem. 2016, 804, 108-113. [CrossRef]

53. De Nino, A.; Maiuolo, L.; Costanzo, P.; Algieri, V.; Jiritano, A.; Olivito, F.; Tallarida., M.A. Recent Progress in Catalytic Synthesis of 1,2,3-Triazoles. Catalysts 2021, 11, 1120. [CrossRef]

54. Jiang, X.; Hao, X.; Jing, L.; Wu, G.; Kang, D.; Liu, X.; Zhan, P. Recent applications of click chemistry in drug discovery. Expert Opin. Drug Discov. 2019, 14, 779-789. [CrossRef]

55. Bozorov, K.; Zhao, J.; Aisa, H.A. 1,2,3-Triazole-containing hybrids as leads in medicinal chemistry: A recent overview. Bioorg. Med. Chem. 2019, 27, 3511-3531. [CrossRef] 
56. Tron, G.C.; Pirali, T.; Billington, R.A.; Canonico, P.L.; Sorba, G.; Genazzani, A.A. Click chemistry reactions in medicinal chemistry: Applications of the 1,3-dipolar cycloaddition between azides and alkynes. Med. Res. Rev. 2008, 28, 278-308. [CrossRef]

57. Lutz, J.F.; Zarafshani, Z. Efficient construction of therapeutics, bioconjugates, biomaterials and bioactive surfaces using azidealkyne "click" chemistry. Adv. Drug Deliv. Rev. 2008, 60, 958-970. [CrossRef]

58. Amblard, F.; Cho, J.H.; Schinazi, R.F. Cu(I)-Catalyzed Huisgen Azide-Alkyne 1,3-Dipolar Cycloaddition Reaction in Nucleoside, Nucleotide, and Oligonucleotide Chemistry. Chem. Rev. 2009, 109, 4207-4220. [CrossRef]

59. Lutz, J.-F. 1,3-Dipolar Cycloadditions of Azides and Alkynes: A Universal Ligation Tool in Polymer and Materials Science. Angezw. Chem. Int. Ed. 2007, 46, 1018-1025. [CrossRef]

60. Binder, W.H.; Sachsenhofer, R. ‘Click' Chemistry in Polymer and Materials Science. Macromol. Rapid Commun. 2007, 28, 15-54. [CrossRef]

61. Meldal, M. Polymer “Clicking” by CuAAC Reactions. Macromol. Rapid Commun. 2008, 29, 1016-1051. [CrossRef]

62. Juríček, M.; Kouwer, P.H.J.; Rowan, A.E. Triazole: A unique building block for the construction of functional materials. Chem. Commun. 2011, 47, 8740-8749. [CrossRef]

63. Espeel, P.; Du Prez, F.E. “Click"-Inspired Chemistry in Macromolecular Science: Matching Recent Progress and User Expectations. Macromolecules 2015, 48, 2-14. [CrossRef]

64. Delaittre, G.; Guimard, N.K.; Barner-Kowollik, C. Cycloadditions in Modern Polymer Chemistry. Acc. Chem. Res. 2015, 48, 1296-1307. [CrossRef]

65. Hayeebueraheng, A.; Kaewmee, B.; Rukachaisirikul, V.; Kaeobamrung, J. Synthesis of 2-(1,2,3-Triazolyl)benzamide Derivatives by a Copper(I)-Catalyzed Multicomponent Reaction. Eur. J. Org. Chem. 2017, 2017, 6714-6721. [CrossRef]

66. Schreiner, E.; Wilcke, T.; Müller, T.J.J. A sequentially copper-catalyzed alkyne carboxylation-propargylation-azide cycloaddition (CuACPAC) synthesis of 1,2,3-triazolylmethyl arylpropiolates. Synlett 2016, 27, 379-382. [CrossRef]

67. Nepveu, F.; Najahi, E.; Valentin, A. Antimalarial Activities of Indolones and Derivatives. Curr. Top. Med. Chem. 2014, 14, 1643-1652. [CrossRef]

68. Yu, B.; Yu, D.-Q.; Liu, H.-M. Spirooxindoles: Promising scaffolds for anticancer agents. Eur. J. Med. Chem. 2015, 97, 673-698. [CrossRef]

69. Ye, N.; Chen, H.; Wold, E.A.; Shi, P.Y.; Zhou, J. Therapeutic Potential of Spirooxindoles as Antiviral Agents. ACS Infect. Dis. 2016, 2, 382-392. [CrossRef]

70. Schönhaber, J.; D’Souza, D.M.; Glißmann, T.; Mayer, B.; Janiak, C.; Rominger, F.; Frank, W.; Müller, T.J.J. Domino InsertionCoupling Synthesis of Solid-State Luminescent Propynylidene Indolones. Chem. Eur. J. 2018, 24, 14712-14723. [CrossRef]

71. Denißen, M.; Nirmalanathan, N.; Behnke, T.; Hoffmann, K.; Resch-Genger, U.; Müller, T.J.J. 3-Piperazinyl propenylidene indolone merocyanines-Consecutive three-component synthesis and electronic properties of solid state luminophores with AIE properties. Mater. Chem. Front. 2017, 1, 2013-2026. [CrossRef]

72. Denißen, M.; Hannen, R.; Itskalov, D.; Biesen, L.; Nirmalananthan-Budau, N.; Hoffmann, K.; Reiss, G.J.; Resch-Genger, U.; Müller, T.J.J. One-pot Synthesis of a White-light Emissive Bichromophore Operated by Aggregation-induced Dual Emission (AIDE) and Partial Energy Transfer. Chem. Comm. 2020, 56, 7407-7410. [CrossRef] [PubMed]

73. Elsner, A.-L.; Biesen, L.; Müller, T.J.J. Pseudo-Five-component Synthesis of Indolone-3-aminopropenylidene Merocyanine Dimers and Their Attenuated Aggregation-Induced Emission. Arkivoc 2021, 2021, 53-66. [CrossRef]

74. McAteer, C.H.; Murugan, R.; Yamamoto, J.H. Pyridines and Their Benzo Derivatives: Applications. In Comprehensive Heterocyclic Chemistry IV; StC Black, D., Cossy, J., Stevens, C.V., Eds.; Volume 7: Six-Membered Rings with One Heteroatom and Their Fused Carbocyclic Derivatives; Elsevier: Amsterdam, The Netherlands, 2022; Volume 7.06, pp. 217-242. [CrossRef]

75. Khan, I.; Ibrar, A.; Abbas, N.; Saeed, A. One-pot access to a privileged library of six membered nitrogenous heterocycles through multi-component cascade approach. Res. Chem. Intermed. 2016, 42, 5147-5196. [CrossRef]

76. Driowya, M.; Saber, A.; Marzag, H.; Demange, L.; Benhida, R.; Bougrin, K. Microwave-Assisted Synthesis of Bioactive SixMembered Heterocycles and Their Fused Analogues. Molecules 2016, 21, 492. [CrossRef] [PubMed]

77. Dohe, J.; Müller, T.J.J. Consecutive Three- and Four-component Coupling-Bagley-Bohlmann-Rahtz Syntheses of Tri- and Tetrasubstituted Pyridines. Z. Naturforsch. 2016, 71, 705-718. [CrossRef]

78. Bakulina, O.; Merkt, F.K.; Knedel, T.O.; Janiak, C.; Müller, T.J.J. Water-soluble Blue Emissive Tricyclic 2-Aminopyridinium Salts by Three-component Coupling-(3+3)-Anellation Synthesis. Angew. Chem. Int. Ed. 2018, 57, 17240-17244. [CrossRef]

79. Cao, T.; Martini, M.L.; Park, K.-S.; Kaniskan, H.Ü.; Jin, J. Pyrimidines and Their Benzo Derivatives. In Comprehensive Heterocyclic Chemistry IV; StC Black, D., Cossy, J., Stevens, C.V., Eds.; Volume 8: Six-Membered Rings with One Heteroatom and Their Fused Carbocyclic Derivatives; Elsevier: Amsterdam, The Netherlands, 2022; Volume 8.02, pp. 86-228. [CrossRef]

80. Cheremnykh, K.P.; Savel'ev, V.; Shkurko, O.P.; Shults, E.E. Synthesis of hybrid molecules containing pyrimidine and diterpene alkaloid lappaconitine fragments. Chem. Heterocycl. Compd. 2018, 54, 1131-1138. [CrossRef]

81. Dömling, A.; Ugi, I. Multicomponent Reactions with Isocyanides. Angew. Chem. Int. Ed. 2000, 39, 3168-3210. [CrossRef]

82. Moni, L.; Denißen, M.; Valentini, G.; Müller, T.J.J.; Riva, R. Diversity-oriented synthesis of intensively blue emissive 3hydroxyisoquinolines by sequential Ugi four-component reaction-reductive Heck cyclization. Chem. Eur. J. 2015, 21 , 753-762. [CrossRef] 
83. Moni, L.; Gers-Panther, C.F.; Anselmo, M.; Müller, T.J.J.; Riva, R. Highly Convergent Synthesis of Intensively Blue Emissive Furo[2,3c]isoquinolines by a Palladium-catalyzed Cyclization Cascade of Unsaturated Ugi Products. Chem. Eur. J. 2016, 22, $2020-2031$. [CrossRef]

84. Huigens III, R.W.; Tenneti, S.; Xiao, T.; Garrison, A.T. Pyrazines and Their Benzo Derivatives. In Comprehensive Heterocyclic Chemistry IV; StC Black, D., Cossy, J., Stevens, C.V., Eds.; Volume 8: Six-Membered Rings with One Heteroatom and Their Fused Carbocyclic Derivatives; Elsevier: Amsterdam, The Netherlands, 2022; Volume 8.03, pp. 229-282. [CrossRef]

85. Gers, C.F.; Nordmann, J.; Kumru, C.; Frank, W.; Müller, T.J.J. Highly Solvatochromic Fluorescent 2-Substituted 3-Ethynyl Quinoxalines-Four-component Synthesis, Photophysical Properties, and Electronic Structure. J. Org. Chem. 2014, 79, 3296-3310. [CrossRef]

86. Gers-Panther, C.F.; Fischer, H.; Nordmann, J.; Seiler, T.; Behnke, T.; Würth, C.; Frank, W.; Resch-Genger, U.; Müller, T.J.J. Four- and Five-component Syntheses and Photophysical Properties of Emission Solvatochromic 3-Aminovinylquinoxalines. J. Org. Chem. 2017, 82, 567-578. [CrossRef]

87. Merkt, F.K.; Höwedes, S.P.; Gers-Panther, C.F.; Gruber, I.; Janiak, C.; Müller, T.J.J. Three-component Activation-AlkynylationCyclocondensation (AACC) Synthesis of Enhanced Emission Solvatochromic 3-Ethynyl Quinoxalines. Chem. Eur. J. 2018, 24, 8114-8125. [CrossRef]

88. Merkt, F.K.; Müller, T.J.J. Synthesis and Electronic Properties of Expanded 5-(Hetero)Aryl-Thien-2-yl Substituted 3-Ethynyl Quinoxalines with AIE Characteristics. Sci. China Chem. 2018, 61, 909-924. [CrossRef]

89. Merkt, F.K.; Pieper, K.; Klopotowski, M.; Janiak, C.; Müller, T.J.J. Sequential Cu-catalyzed Four- and Five-Component Syntheses of Luminescent 3 Triazolylquinoxalines. Chem. Eur. J. 2019, 25, 9447-9455. [CrossRef]

90. Cordero, F.M.; Giomi, D.; Machetti, F. Isoxazoles. In Comprehensive Heterocyclic Chemistry IV; StC Black, D., Cossy, J., Stevens, C.V., Eds.; Volume 4: Five-Membered Rings with Two Heteroatoms and Their Fused Carbocyclic Derivatives; Elsevier: Amsterdam, The Netherlands, 2022; Volume 4.03, pp. 308-434

91. Görgen, C.; Müller, T.J.J. Facile Consecutive Three-Component Synthesis of 3,5-Disubstituted Isoxazoles. Chem. Heterocycl. Compd. 2017, 53, 422-429. [CrossRef]

92. Thirukovela, N.S.; Balabiona, R.; Botla, V.; Vadde, R.; Jonnalagadda, S.B.; Vasam, C.S. One-pot regioselective synthesis of substituted pyrazoles and isoxazoles in PEG-400/water medium by Cu-free nano-Pd catalyzed sequential acyl Sonogashira coupling-intramolecular cyclization. Catal. Sci. Technol. 2019, 9, 6471-6481. [CrossRef]

93. Deden, T.; May, L.; Reiss, G.J.; Müller, T.J.J. Rapid Sequentially Palladium Catalyzed Four-Component Synthesis of Novel Fluorescent Biarylsubstituted Isoxazoles. Catalysts 2020, 10, 1412. [CrossRef]

94. Kaldre, D. Pyrans and Benzo Derivatives: Applications. In Comprehensive Heterocyclic Chemistry IV; StC Black, D., Cossy, J., Stevens, C.V., Eds.; Volume 7: Six-Membered Rings with One Heteroatom and Their Fused Carbocyclic, Derivatives; Elsevier: Amsterdam, The Netherlands, 2022; Volume 7.09, pp. 491-511. [CrossRef]

95. Breuer, N.; Müller, T.J.J. Consecutive Alkynylation-Michael Addition-Cyclocondensation (AMAC) Multicomponent Syntheses of $\alpha$-Pyrones and $\alpha$-Pyridones. Synthesis 2018, 50, 2741-2752.

96. Breuer, N.; Gruber, I.; Janiak, C.; Müller, T.J.J. Emission solvatochromic, solid-state and aggregation-induced emissive $\alpha$-pyrones and emission-tuneable $1 H$-pyridines by Michael addition-cyclocondensation sequences. Beilstein J. Org. Chem. 2019, 15, $2684-2703$. [CrossRef]

97. Papadopoulos, J.; Merkens, K.; Müller, T.J.J. Three-Component Synthesis and Photophysical Properties of Novel Coumarin-based Merocyanines. Chem. Eur. J. 2018, 24, 974-983. [CrossRef]

98. Macedo, F.P.; Gwengo, C.; Lindeman, S.G.; Smith, M.D.; Gardinier, J.R. $\beta$-Diketonate, $\beta$-Ketoiminate, and $\beta$-Diiminate Complexes of Difluoroboron. Eur. J. Inorg. Chem. 2008, 2008, 3200-3211. [CrossRef]

99. Dohe, J.; Koßmann, J.; Müller, T.J.J. Diversity-oriented Four-component Synthesis of Solid State Luminescent Difluoro Oxazaborinines. Dyes Pigm. 2018, 157, 198-217. [CrossRef]

100. Bertaina-Anglade, V.; La Rochelle, C.D.; Scheller, D.K.A. Antidepressant properties of rotigotine in experimental models of depression. Eur. J. Pharmacol. 2006, 548, 106-114. [CrossRef]

101. Guo, X.; Baumgarten, M.; Müllen, K. Designing pi-conjugated polymers for organic electronics. Prog. Polym. Sci. 2013, 38, 1832-1908. [CrossRef]

102. Schaper, K.; Müller, T.J.J. Thiophene Syntheses by Ring Forming Multicomponent Reactions. Top. Curr. Chem. 2019, 376, 261-283.

103. Teiber, M.; Giebeler, S.; Lessing, T.; Müller, T.J.J. Efficient pseudo-five-component coupling-Fiesselmann synthesis of luminescent oligothiophenes and their modification. Org. Biomol. Chem. 2013, 11, 3541-3552. [CrossRef]

104. Breuer, N.; Müller, T.J.J. Synthesis and Electronic Properties of 5,5"-Diacceptor Substituted Terthiophenes. Dyes Pigm. 2018, 149, 676-685. [CrossRef] 